\title{
High Elongation Thermoplastic Polyester-Urethanes Based on Widely Available Diacid Intermediates
}

\author{
Marion Tharcis ${ }^{1}$, Thierry Badel ${ }^{2}$, Stéphane Jéol ${ }^{2}$, Etienne Fleury ${ }^{1}$, Françoise Méchin ${ }^{1 *}$ \\ ${ }^{1}$ Université de Lyon, CNRS, UMR 5223, INSA-Lyon, IMP@INSA, F-69621, Villeurbanne, France \\ ${ }^{2}$ Solvay Research \& Innovation - Centre Lyon - BP62 - 69192 Saint-Fons, France \\ Correspondence to: Françoise Méchin (E-mail : francoise.mechin@insa-lyon.fr)
}

((Additional Supporting Information may be found in the online version of this article.))

\begin{abstract}
A series of new $\alpha, \omega$-dihydroxy terminated polyester oligomers are synthesized from the condensation reaction of various aliphatic diols with a mixture of diacids rich in 2-methylglutaric acid, MGA, an abundant and well-defined industrial product. Their adipic acid (AA)-based counterparts are also prepared and the physico-chemical properties of both types of polyols are thoroughly characterized.

All these polyester polyols are then used to prepare segmented polyurethanes following a two-stage process, by reacting them successively with 4,4'-diphenylmethane diisocyanate, and 1,4butanediol. The resulting materials are then evaluated with respect to their thermal and dynamic or static mechanical properties. The observed characteristics and behaviors are quite similar between AA- or MGA-based polyurethanes, except for the tendency of AA-based samples to display partially crystallized soft domains. Such a phenomenon is prevented in MGA-based samples because of the methyl side group, resulting in remarkably higher ultimate elongations for the new thermoplastic polyurethanes derived from MGA.
\end{abstract}

KEYWORDS : polyurethanes; polyester-polyol; 2-methylglutaric acid; elastomers; mechanical properties; crystallinity; elongation at break

Published in Journal of Applied Polymer Science Vol. 133, \#43410 (2016) 


\section{INTRODUCTION}

Thermoplastic polyurethanes and polyurethane-ureas, TPUs, are an important family of highperformance engineering thermoplastics and elastomers. Due to the versatility of their formulation traditionally based on three main components, i.e. a dihydroxy-terminated oligomer or "macrodiol" with a typical molar mass ranging from 600 to $4000 \mathrm{~g} \cdot \mathrm{mol}^{-1}$ (often polyether or polyester, and itself based on a wide variety of possible precursors), a diisocyanate and a short diol or diamine known as "chain extender", a huge range of materials with adjustable thermal or mechanical behaviors and processing methods can be obtained. But despite this theoretical adaptability, in practice TPU formulations are often based on a very limited number of precursors. For example, the diisocyanate is predominantly 4,4'-bis(isocyanatophenyl)methane, MDI, while 1,4-butanediol is most often used as the chain extender. As well, a great part of the TPUs commercialized worldwide are indeed based on a few polyester macrodiols, and for the most part derived either from polycaprolactone (e.g. biodegradable materials) or from the condensation of various diols with adipic acid. Yet over the years, lots of academic works were devoted to the preparation of TPUs from more or less modified crude vegetable oils containing ester groups. ${ }^{[1-5]}$ More recently, soft TPUs were even obtained from polyester polyols based on purified dicarboxylic or hydroxylated-carboxylated molecules derived from triglycerides from seed oils; ${ }^{[6,7]}$ but the possibility of industrial transposition of these syntheses often still needs further proof. Attempts were otherwise made to synthesize new TPUs from polyester polyols based on the renewable succinic acid, and to compare them with polyadipatebased counterparts. ${ }^{[8]}$ Both TPU families were found to differ essentially by the degree of crystallinity of their soft segments, by their glass transition temperatures and by the nature and intensity of the physico-chemical interactions between soft and hard phases.

The production of polyurethanes accounts for $\sim 5 \%$ of the total adipic acid consumption worldwide. Adipic acid, AA is traditionally produced from petroleum-based feedstocks, and more specifically from a 2-stage oxidation of cyclohexane. ${ }^{[9]}$ However, various mixtures of aliphatic carboxylic acids are now easily available from the conversion of the corresponding nitriles obtained as by-products in the hydrocyanation of butadiene. ${ }^{[10,11]}$ Among these, the diacid blend used in this work, Rhodiacid ${ }^{\mathrm{TM}}$-MGA, is a mixture of 3 chain isomers of adipic acid rich in 2-methylglutaric acid. The use of this blend as the basis of new polyester polyols would represent a way of giving value to a current product of the polyamide industry. However to the best of our knowledge, in the academic literature no polyurethane materials were ever prepared and fully characterized from this kind of diacid blend that is only mentioned in a patent by BASF. ${ }^{[12]}$ Indeed the effect of the presence of alkyl side groups in the polyester soft segments of polyurethane elastomers on their physical properties (mechanical or thermal behavior and hydrolysis resistance) was mainly studied by modifying the chemical structure of the starting diol, but scarcely by playing on the diacid structure. ${ }^{[13-15]}$ Moreover a recent study proved that high molar mass thermoplastic polyesters based on MGA could display equivalent toughness together with higher values of elongation at failure when compared with counterparts based on linear aliphatic diacids and especially adipic acid. ${ }^{[16]}$ Therefore in the present work, after synthesizing and thoroughly characterizing a series of polyester polyols from the novel diacid MGA, together with their AA-based analogs, linear segmented polyurethanes were obtained from their condensation with 4,4'-diphenylmethane diisocyanate and 1,4-butanediol. The thermal 
and dynamic and static mechanical properties of the resulting materials were then systematically compared.

\section{EXPERIMENTAL}

\section{Materials}

The polyester polyols were synthesized by Solvay at lab-scale and then used as received, though after being thoroughly characterized. For polyurethane elastomer synthesis, they were reacted with pure 4,4'-diisocyanatodiphenylmethane, $\mathrm{MDI}$, and 1,4-butanediol, BDO, both from Sigma Aldrich France. These precursors were used as received.

\section{Thermoplastic Polyurethane Synthesis}

Series of TPUs derived from all the above polyester polyols, MDI and BDO, and containing various amounts of hard segments, HS\% were successively prepared (for each formulation 30,40 or

50 wt $\%$ with $H S \%=\frac{m_{M D I}+m_{B D O}}{m_{\text {polyol }}+m_{M D I}+m_{B D O}}$, in which $m_{i}$ is the total mass of component $i$ used for the synthesis). These materials were named as (name of the polyol)-X\% with $\mathrm{X}$ the HS weight\%.

In a typical synthesis (the following data refer to the sample MGA-BDO-1-40\%, see Results \& Discussion - Thermoplastic Polyurethane Synthesis section and Table S1 in Supplementary Material for composition), both the polyol and the chain extender BDO were first thoroughly dried under a vacuum at $80^{\circ} \mathrm{C}$ for 2 hours. Prior to the synthesis, the hydroxyl number of the polyols and NCO \% of the diisocyanate, MDI were checked by chemical titration to ensure a perfect adjustment of stoichiometry. In a glass reactor equipped with a mechanical stirrer (flat impeller with multiple, regularly distributed circular holes) with vacuum/nitrogen inlet, MDI (17.68 g) was first weighed then molten and heated up to $80^{\circ} \mathrm{C}$; afterwards, the proper amount of polyol ([NCO]/[OH] > 1) (MGABDO-1, $32.81 \mathrm{~g}$ ) was added and the mixture allowed to react. It usually became homogeneous and transparent within $5-10 \mathrm{~min}$ at $80^{\circ} \mathrm{C}$. After 30 minutes stirring (see $\S 3.3$ ), the flask was removed from the oil bath 3-5 min before the previously weighed proper amount of BDO (4.15 g) could be added with the help of a syringe and the increasingly viscous mixture was homogenized by vigorous stirring for 1-2 min. It was then degassed under vacuum and then rapidly cast in a previously warmed flat metal mold. Homogeneous plates with a regular thickness about $1.3 \mathrm{~mm}$ were obtained by curing under a hot press ( 4 tons, $110^{\circ} \mathrm{C}$ ) for $18 \mathrm{~h}$ and cooling back to room temperature under ambient conditions. In some cases (high HS\%) the samples had to be initially pressed at higher temperature $\left(180-200^{\circ} \mathrm{C}\right.$ ) for about 5 minutes before being cured at $110^{\circ} \mathrm{C}$. Cylindrical small but thicker pieces (> 6 $\mathrm{mm}$ ) were also molded to allow the measurement of Shore hardness with a hand durometer (AFNOR standard NF T46-052).

\section{Size Exclusion Chromatography}

All the prepared materials were first characterized by Size Exclusion Chromatography, SEC. A high molar mass is indeed required to measure representative mechanical properties for the different materials and to be able to compare samples with one another. SEC was carried out using either tetrahydrofurane, $\mathrm{THF}$, at $35^{\circ} \mathrm{C}$ (for oligodiols) or dimethylformamide, $\mathrm{DMF},+\mathrm{LiBr}(0.05 \mathrm{M})$ at $70^{\circ} \mathrm{C}$ (for oligodiols and TPUs) as eluent. The THF flow rate was $1.0 \mathrm{~mL} / \mathrm{min}$ and that of DMF 0.8 $\mathrm{mL} / \mathrm{min}$. Analyses were run on a Viscotek chromatograph equipped with 3 Styragel HR 4E columns; 
detectors consisted of a differential refractometer VE3580 and a Dual T60A detector (combining a right angle light scattering detector and a viscosimeter), allowing the determination of absolute molar masses after evaluating $\mathrm{dn} / \mathrm{dc}$ for all the samples. This was done in DMF for all the synthesized TPUs by injecting samples with 3 different concentrations. These measurements led to values ranging from 0.052 to $0.077 \mathrm{~mL} / \mathrm{g}$, with the highest data systematically associated with the highest HS\%.

\section{${ }^{1} \mathrm{H}$ Nuclear Magnetic Resonance}

The chemical structure of the starting polyols was characterized by ${ }^{1} \mathrm{H}$ NMR spectroscopy performed on a Bruker DRX 400 spectrometer operating at 250 or $400 \mathrm{MHz}$. Samples were dissolved in $\mathrm{CDCl}_{3}$. In some cases, a few drops of trifluoroacetic acid were added in order to shift the signals of the labile protons.

\section{Chemical Determinations}

The precise knowledge of the hydroxyl number of a macrodiol, $\mathrm{i}_{\mathrm{OH}}$, is essential for the proper synthesis of polyurethane materials, since an optimal stoichiometry is required to obtain high molar masses and good mechanical properties. In this work the values retrieved from NMR spectra were compared with those calculated from chemical determination. For this purpose, the conventional method using p-toluene sulfonyl isocyanate (TSI) (ASTM E1899-08) had to be somewhat adapted. Here the polyols were first thoroughly dried under a vacuum at $80^{\circ} \mathrm{C}$ for at least 2 hours. They were then dissolved in anhydrous THF and reacted with a known excess of TSI (Aldrich) for 2 hours. A solution of $\mathrm{N}, \mathrm{N}$-dibutylamine in anhydrous THF ( $2 \mathrm{M})$ was then added and the mixture was allowed to react 15 more minutes. The residual amine was finally back titrated using a $1 \mathrm{~N}$ hydrochloric acid solution. The accuracy of this method was checked with simple aliphatic alcohols such as 1,4butanediol.

The acid numbers, $\mathrm{i}_{\mathrm{COOH}}$ were determined by the supplier after an acido-basic titration.

Finally, a chemical determination (AFNOR standard NF T52-132) was sometimes used to check MDI purity or to monitor the consumption of NCO groups during the polyol-MDI addition reaction. For this purpose samples were regularly collected, weighed and reacted with a known excess of $\mathrm{N}, \mathrm{N}$-di( $n$-butylamine). The residual amine was finally back titrated with $1 \mathrm{~N} \mathrm{HCl}$, and the resulting isocyanate contents were expressed by the NCO percentage:

$$
I_{N C O} \%=100 \times \frac{42.02}{\text { NCO equivalent weight (in } g)}
$$

\section{Differential Scanning Calorimetry}

The thermal behavior of the various polyols and polyurethane materials was studied by differential scanning calorimetry, DSC, using a TA Q22 apparatus. Samples ( $\sim 4-7 \mathrm{mg}$ ) were heated from -100 to $200^{\circ} \mathrm{C}$ (polyols) or -80 to $250^{\circ} \mathrm{C}$ (polyurethanes) under nitrogen. Two heating ramps $(20 \mathrm{~K} / \mathrm{min})$ were successively performed with intermediate cooling at the same rate.

\section{Thermogravimetric Analysis}

Small samples $\left(\mathrm{m}<10 \mathrm{mg}\right.$ ) were heated at $10 \mathrm{~K} / \mathrm{min}$ from room temperature up to $580^{\circ} \mathrm{C}$ under air or nitrogen. The analyses were run on a Q500 apparatus from TA Instruments. 


\section{Viscosity Measurements}

The viscosity of the polyols was measured with an Anton Paar MCR301 rheometer, using a cone/plate geometry. Isothermal time sweep experiments were run in the linear domain of the samples (strain $2 \%$ ) at 2 or 3 different temperatures: $25^{\circ} \mathrm{C}$ (only for amorphous liquid samples), 50 and $80^{\circ} \mathrm{C}$.

\section{Tensile Testing}

Uniaxial tensile measurements were carried out on a MTS 2/M electromechanical testing system at $22 \pm 1^{\circ} \mathrm{C}$ and $50 \pm 5 \%$ relative humidity. H3-type dumb-bell specimens (AFNOR T51-034) were cut from the cast plates with a $10 \mathrm{~mm}$ nominal gauge length and an approximately $1.3 \times 4 \mathrm{~mm}$ cross-sectional area. These samples were tested with a $20 \mathrm{~mm} / \mathrm{min}$ constant speed, with the help of an extensometer and pneumatic grips, in order to determine Young's modulus, E, the ultimate stress, $\sigma_{R}$, and ultimate elongation, $\varepsilon_{R}$, and finally the secant moduli for $100 \%$ or $300 \%$ strain. For each material, 3 to 5 specimens were tested.

For hysteresis measurements, the test consisted of 10 tensile loads from 0 to either $100 \%$, $400 \%$ or $800 \%$ deformation with a crosshead speed of $50 \mathrm{~mm} / \mathrm{min}$.

\section{Dynamic Mechanical Thermal Analysis (DMTA)}

DMTA experiments were carried out on a Rheometrics Solid Analyzer RSA II at $1 \mathrm{~Hz}$ with $0.1 \%$ tensile strain. The heating rate was $3^{\circ} \mathrm{C} / \mathrm{min}$ for the temperature range from -100 to $+225^{\circ} \mathrm{C}$. The size of the samples cut from the cast plates was approximately $40 \times 8 \times 1.3 \mathrm{~mm}$.

\section{RESULTS AND DISCUSSION}

\section{Polyester Macrodiols Synthesis}

A typical synthesis can be described as follows: both monomers, the diol and the diacid, were poured in a glass reactor equipped with a mechanical stirrer with vacuum/nitrogen inlet and a distillation column followed by a condenser. The diol/diacid ratio was determined considering the final molar mass expected after full conversion, always with an excess of hydroxyl functions. For instance, for the polyol AA-1,6-hexanediol (HDO) targeting $1000 \mathrm{~g} / \mathrm{mol}$, the molar ratio diol/diacid = 1.25 was fixed. Then the nitrogen inlet was opened and the temperature was increased progressively to $140^{\circ} \mathrm{C}$, with continuous stirring, and kept for $1 \mathrm{~h}$ at this temperature. Condensation started. The mixture was then slowly heated up to $240^{\circ} \mathrm{C}$ and kept at this temperature for $3 \mathrm{~h}$. No catalyst was used. Then the heater was stopped and the adduct was let to cool down to room temperature. The day after the temperature was progressively increased back to $240^{\circ} \mathrm{C}$ under nitrogen, then nitrogen was stopped and vacuum was set for $4 \mathrm{~h} 30 \mathrm{~min}$. The heater was stopped, the vacuum was stopped and replaced by nitrogen flow and the adduct was allowed to cool down to about $100^{\circ} \mathrm{C}$ and finally poured in a glass bottle.

\section{Physico-Chemical Characterization of the Polyester Macrodiols}

The new diacid used for the polyester polyols synthesis was Rhodiacid ${ }^{\text {TM}}$-MGA. This proprietary blend is obtained by conversion of a byproduct in the synthesis of polyamide 6.6 through the hydrolysis of 2 -methylglutaronitrile, possibly via a cyclic imide intermediate. ${ }^{[10,11]}$ Its main components are indicated in Scheme 1. 
<smiles>CC(CCC(=O)O)C(=O)O</smiles>

2-methylglutaric acid (MGA)<smiles>CCC(CC(=O)O)C(=O)O</smiles>

2-ethylsuccinic acid (ESA)<smiles>O=C(O)CCCCC(=O)O</smiles>

adipic acid (AA)

Scheme 1. Constituents of Rhodiacid ${ }^{T M}-M G A$

Several oligomers were synthesized from the polyaddition of Rhodiacid ${ }^{\text {TM }}$-MGA with respectively 1,4-butanediol, BDO, 1,6-hexanediol, HDO, and a mixture rich in 2-methyl-1,5pentanediol, "MPDO" ("MPDO" is obtained from the reduction of Rhodiacid"M-MGA and is thus a mixture of 2-methyl-1,5-pentanediol, 2-ethylbutanediol and 1,6-hexanediol). Two series of oligomers with 2 different molar masses, either close to 1000 or $2000 \mathrm{~g} / \mathrm{mol}$, were prepared. For every MGAbased formulation, the corresponding oligomer based on pure adipic acid was also prepared for further comparisons. Hereafter, oligomers will be named from the starting diacid and diol, and from their molar mass as follows: AA-BDO-1 is the polyester oligomer prepared from adipic acid and 1,4butanediol with an expected molar mass around $1000 \mathrm{~g} \cdot \mathrm{mol}^{-1}$; MGA-MPDO-2 is the polyester polyol obtained from Rhodiacid" ${ }^{\text {TM }}$ MGA and “MPDO" with an expected molar mass around 2000 g.mol ${ }^{-1}$.

All the polyester polyols were characterized by ${ }^{1} \mathrm{H} N M R$ in $\mathrm{CDCl}_{3}$, and their hydroxyl number was also systematically determined by chemical titration.

The NMR spectra allowed at first to verify the assumed chemical structure. A typical spectrum obtained for MGA-BDO-1 is displayed in Figure 1.

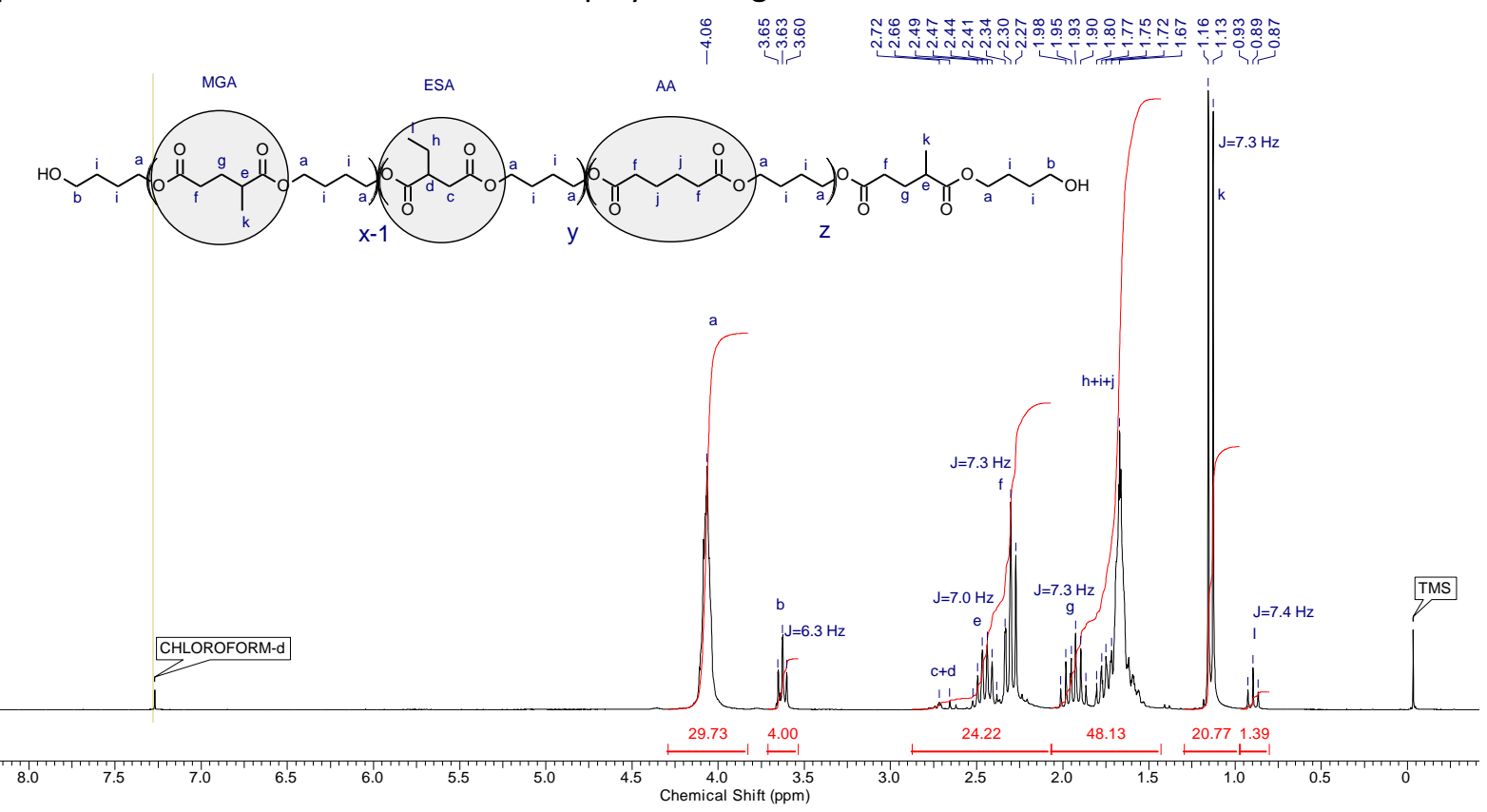

Figure 1: ${ }^{1} \mathrm{H}$ NMR spectrum of sample $\mathrm{MGA-BDO-1}\left(23^{\circ} \mathrm{C}, \mathrm{CDCl}_{3}, 250 \mathrm{MHz}\right)$

Assuming perfectly $\alpha, \omega$-dihydroxytelechelic chains, the comparison of the signals of the $\mathrm{CH}_{2} \mathrm{OH}$ chain ends with respect to those of the central moieties allows the calculation of an average number of constitutive units, $\mathrm{DP}_{\mathrm{n}}$, and of a number average molar mass 
$M_{n}=\left(D P_{n}-1\right) * M_{\text {constitutive unit }}+M_{\text {diol }}$. In the case of MGA- and MPDO-based polyesters, the attributions are more complicated and a matrix calculation has to be used but the data can still be resolved. All the results are listed in Table 1.

In fact, all the chain ends are not $100 \%$ hydroxylated; some of them bear $\mathrm{COOH}$ groups as shown by the measured $i_{\mathrm{COOH}}$ values (see Table 1 ). Therefore, the above calculated values for $M_{n}$ are a little overestimated.

Another way of calculating $M_{n}$ relies on the chemical determination of end groups. Assuming there are only $\mathrm{OH}$ and $\mathrm{COOH}$ terminal groups, $\mathrm{M}_{n}$ is given by Equation (2):

$$
\operatorname{Mn}\left(g \cdot \mathrm{mol}^{-1}\right)=\frac{112200}{I_{O H}+I_{C O O H}}
$$

The values found by titration for the hydroxyl numbers of all the polyols are listed in Table 1, together with the resulting molar masses. For some samples, the amount of water was also controlled but the amounts found were always quite low (Table 1 ).

Under the ordinary conditions used for polyurethane synthesis, in particular those used in this work $\left(110^{\circ} \mathrm{C}\right.$, see below) and in the absence of any suitable catalyst, carboxylic acids are very scarcely reactive towards isocyanate groups. ${ }^{[17,18]}$ However the maximal "degree of polymerization", $\mathrm{P}$, that can be calculated for every final segmented polyurethane from the proportion between $\mathrm{OH}$ and $\mathrm{COOH}$ groups is always high enough to ensure appropriate molar masses for the proper comparison of thermal and mechanical properties. $P$ values (i.e. the number of [macrodioldiisocyanate-extender-diisocyanate] units in the chain) can be calculated from Equation (3):

$$
P=\frac{2 N_{0}}{N_{R B}}
$$

where $N_{0}$ stands for the number of monomer molecules in the initial mixture, and $N_{R B}$ is the number of monofunctional molecules. The results displayed in Table 1 show that the lowest calculated value for $P$ is 46 .

It also appears that all the $M_{n}$ values of the prepared polyols are a little higher than expected, especially for the BDO-based samples with the higher molar mass (closer to 3000 than 2000 g.mol ${ }^{-1}$ ). Therefore these 2 samples were finally named AA-BDO-3 and MGA-BDO-3.

By ${ }^{1} \mathrm{H}$ NMR and size exclusion chromatography, the presence of a small amount of residual starting diol (e.g. 1,4-BDO) was evidenced. But for every polyester polyol this amount was always less than $1 \%$, and as this diol also takes part in the reaction with the diisocyanate no attempt was made to get rid of it.

These polyols were then characterized with respect to their thermal behavior using differential scanning calorimetry. Two different behaviors were observed. Liquid samples were indeed entirely amorphous and displayed only one glass transition at low temperature. In contrast, some polyols were waxy at room temperature and turned out to be semi-crystalline, with a low $T_{\mathrm{g}}$ (varying from -71 to $-56^{\circ} \mathrm{C}$ ) and a melting and/or crystallization temperature around $25-50^{\circ} \mathrm{C}$. More precisely, all the samples derived from linear monomers with no side group (AA-BDO, AA-HDO) showed this kind of behavior, whereas quite logically those bearing methyl and ethyl side groups (AA-MPDO, MGA-BDO, MGA-HDO, MGA-MPDO) were perfectly amorphous. This can be viewed as a first advantage of MGA-based polyester polyols since they do not necessarily require to be heated 
when processed for polyurethane synthesis (particularly by casting). All the DSC results are summed up in Table 2.

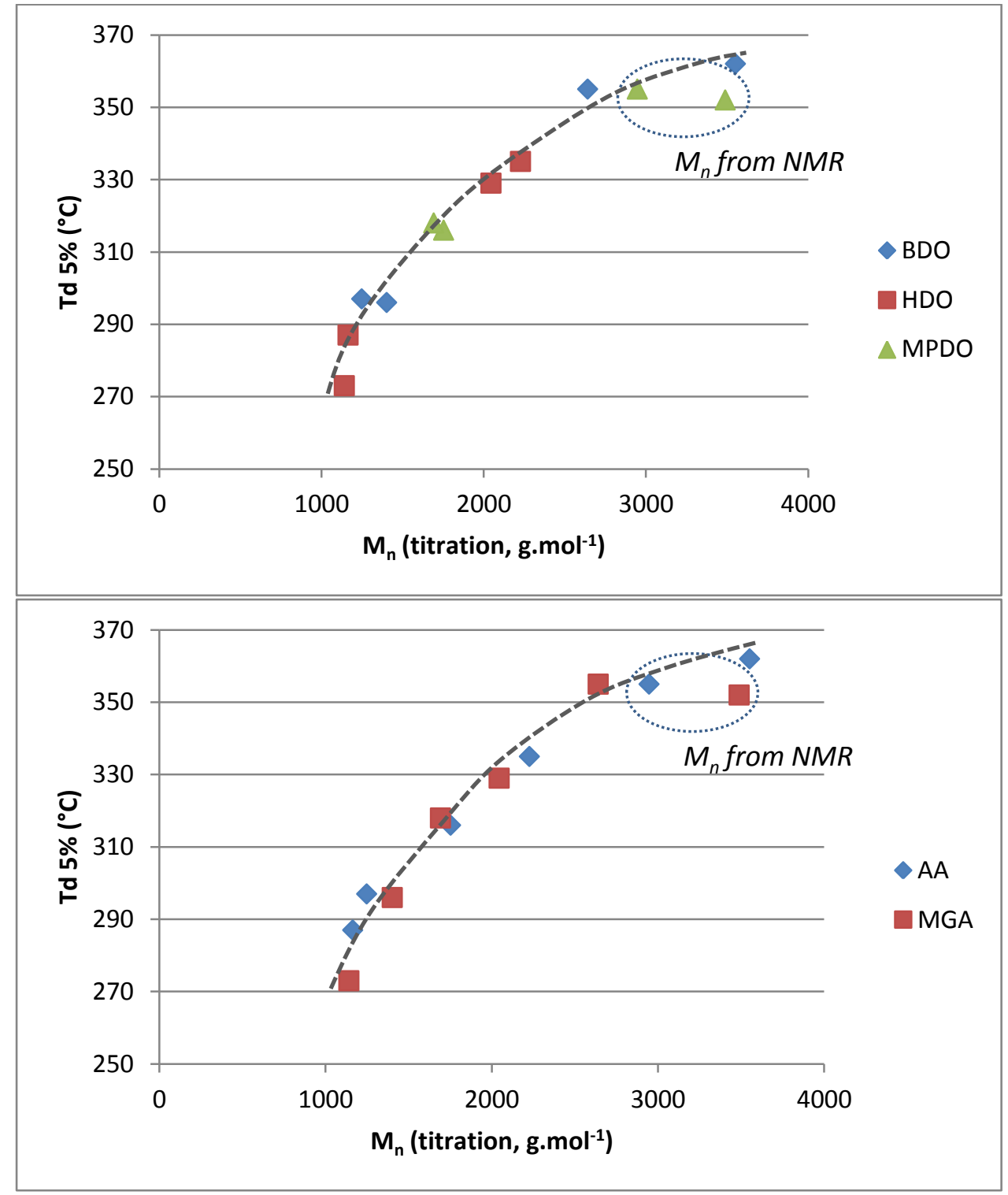

Figure 2. Thermogravimetric analysis of the prepared polyols $\left(10^{\circ} \mathrm{C} / \mathrm{min}\right.$, air)

By thermogravimetric analysis (TGA), the temperature associated with a $5 \%$ weight loss, $T_{d 5} \%$ could be measured and was then plotted vs $M_{n}$ as a function of the nature of the diol or diacids. The results are shown in Figure 2. It appears that the thermal stability of the polyesters increases with their molar mass, suggesting that the first degradation reactions are related to the chain ends; and that it is quite independent from the nature of the starting materials. The entire data lie on the same curve, except for two points that were plotted against overestimated $M_{n}$ values determined from NMR, and would probably fall on the same line if their real $M_{n}$ could have been determined from titration. 


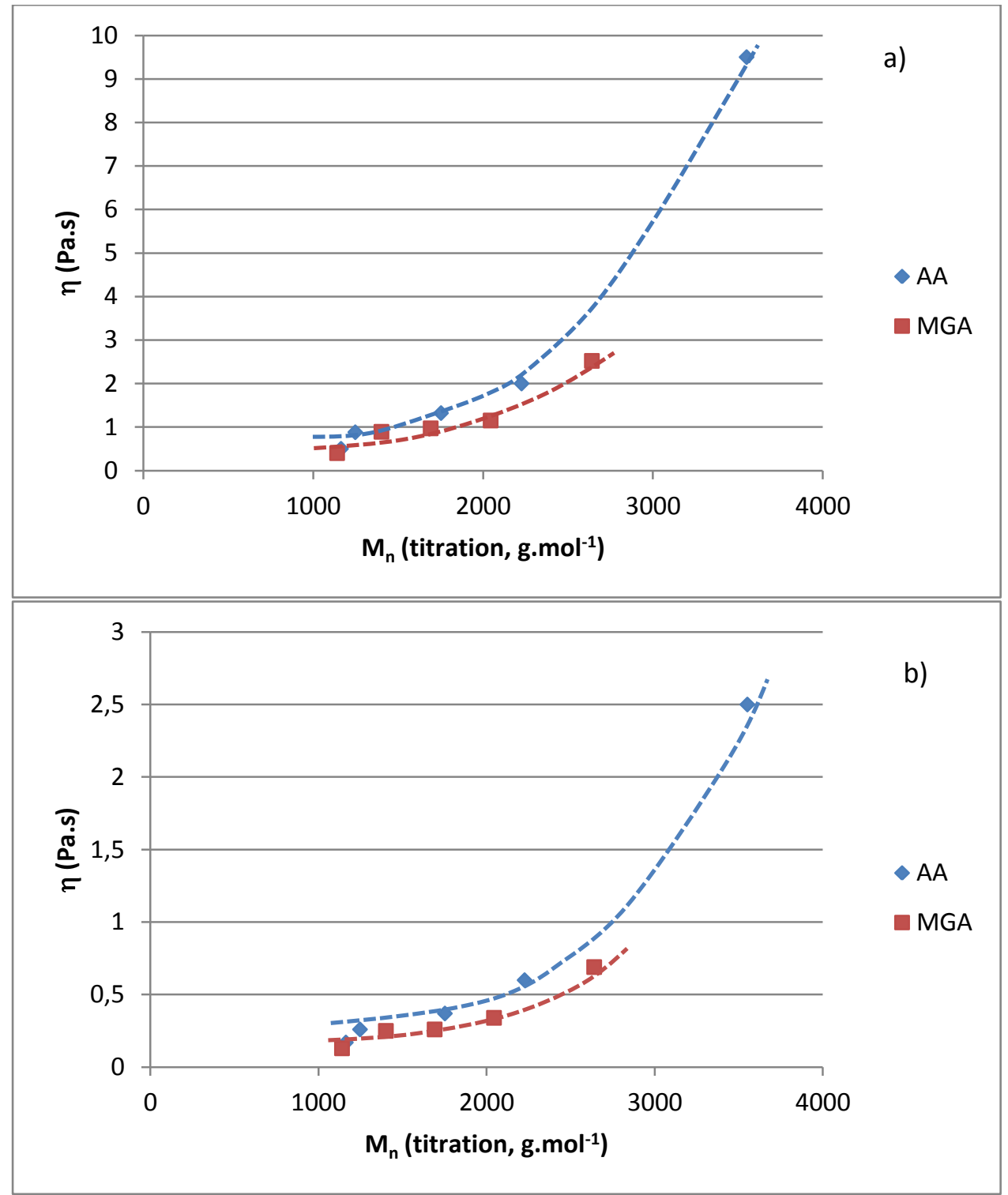

Figure 3. Viscosities of the prepared polyester polyols at a) $50^{\circ} \mathrm{C}$; b) $80^{\circ} \mathrm{C}$

Finally, the complex viscosities were measured at 3 different temperatures, whenever possible. As seen with DSC experiments, the samples based on precursors without side groups were partially crystallized at room temperature and their viscosity could not be measured at $25^{\circ} \mathrm{C}$. But all the polyesters could be characterized at 50 and $80^{\circ} \mathrm{C}$, and the results are given in Figure 3 as a function of the molar mass evaluated from titration. For all the liquid samples, Newtonian behaviors were always observed. While no special variation was observed with respect to the nature of the starting diol, it appears that for a given molar mass and at both studied temperatures, the viscosity is always slightly lower for MGA-based samples than for their AA-based counterpart. This can once again be interesting as far as processing is concerned, since converters could benefit from more limited heating levels using MGA derivatives.

\section{Thermoplastic Polyurethane Synthesis}

To ensure that the first part of the reaction was complete (no remaining hydroxyl groups and a constant NCO concentration), a chemical titration of the residual NCO groups was sometimes used 
to monitor isocyanate conversion. As shown in Figure 4, it appeared that in any case 30 minutes was the optimal time for a complete conversion of all the hydroxyls, without the loss of isocyanate functions through side reactions. In this particular example the expected final conversion for NCO groups was $24 \%$ and was reached after $30 \mathrm{~min}$, while the side reactions apparently began only after $80 \mathrm{~min}$. Therefore 30 minutes was finally the time chosen for the addition of the chain extender BDO for all the syntheses.

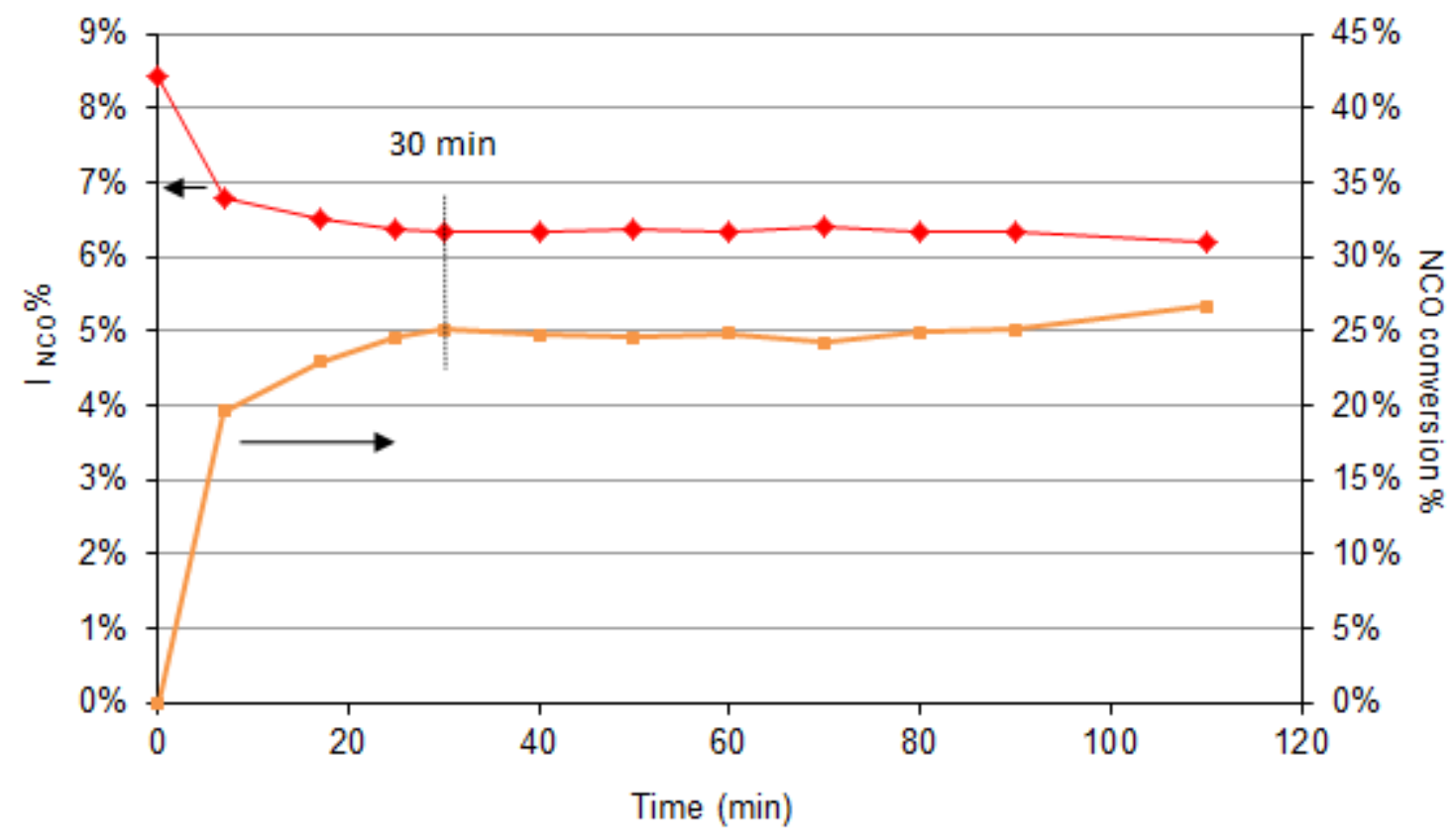

Figure 4. Evolution of the NCO \% ( ) and of the corresponding NCO conversion ( $\square$ ) during the addition reaction between $\mathrm{MDI}$ and $\mathrm{MGA}-\mathrm{BDO}-2$ at $80^{\circ} \mathrm{C}$ under nitrogen $\left([\mathrm{NCO}]_{d} /[\mathrm{OH}]_{0}=4.15\right.$, i.e. expected final conversion $=24 \%$ ).

In order to compensate for the possible loss of some NCO functions by side reactions, the overall $\mathrm{NCO} / \mathrm{OH}$ target ratio was always 1.03 . The precise compositions of all the synthesized materials are available in the Supporting Information (Table S1).

\section{Thermoplastic Polyurethane Characterization}

\section{Molar Masses}

The results obtained for the molar masses are shown in Table 3. Almost all the $M_{n}$ values are higher than $30,000 \mathrm{~g} \cdot \mathrm{mol}^{-1}$ (the lowest 2 still higher than $20,000 \mathrm{~g} \cdot \mathrm{mol}^{-1}$ ), which is sufficient to allow the correct measurement of static and dynamic mechanical properties and more generally ensures a proper interpretation of all the physical data. These high molar masses also confirm that an appropriate stoichiometry was respected for all the syntheses and therefore that the results of the chemical titrations were quite reliable.

\section{Thermal Transitions}

The thermal behaviors of the segmented polyurethanes were then examined by DSC and TGA. All the results are displayed in Table 4, and typical thermograms are shown in Figure 5. 
Figure 5. Typical DSC thermograms obtained for a) MGA-BDO-1 series; b) AA-BDO-3 series; $1^{\text {st }}$ scans in the left column, $2^{\text {nd }}$ scans in the right column
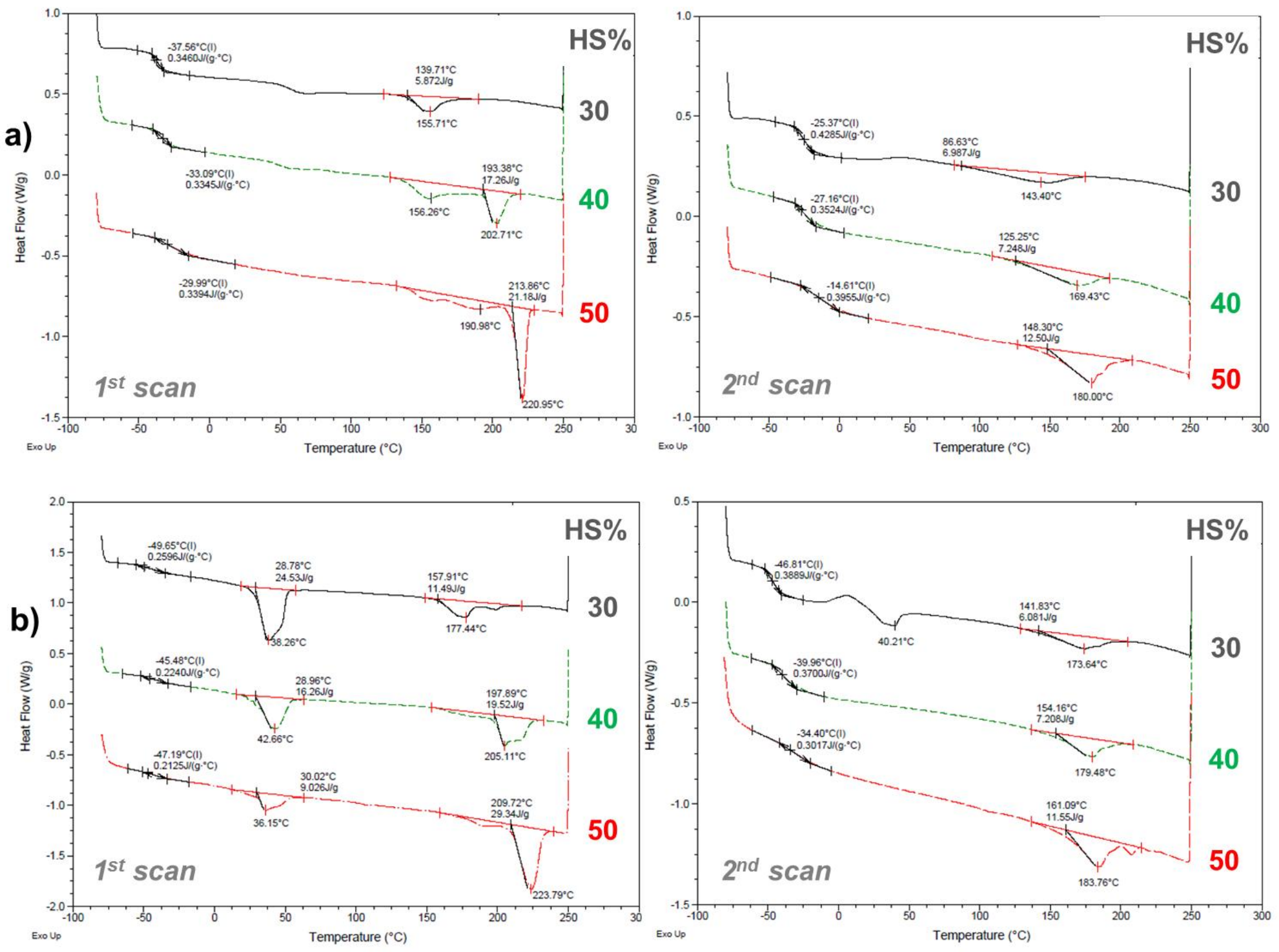
In DSC, 2 successive heating scans were performed with intermediate cooling the same rate $\left(20^{\circ} \mathrm{C} / \mathrm{min}\right)$. The behavior is that classically observed for segmented polyurethanes with successive phenomena associated respectively with the soft and hard domains. In such materials, a soft phase consisting mainly of the soft segments with sometimes dissolved hard segments, separated amorphous hard segments, separated more or less highly ordered hard segments and even crystalline hard segments can coexist at room temperature. ${ }^{[19,20]}$ Here in both heating runs, all the materials show a clear $\mathrm{T}_{\mathrm{g}}$ at low temperature that can be associated with the polyester soft domains. In the first scan, this $\mathrm{T}_{\mathrm{g}}$ lies between -50 and $-24^{\circ} \mathrm{C}$, depending on the sample. In the second scan, the value systematically increases with respect to the first scan, revealing that the hard segments that partially dissolved in the soft phase above the order-disorder transition temperature (or microphase mixing temperature $\mathrm{MMT}$, see below) ${ }^{[21,22]}$ during the first heating run did not have enough time to phase separate during the cooling stage; therefore the soft phase is less pure at the beginning of the second heating ramp and the observed $T_{\mathrm{g}}$ is then higher. In agreement with this, the slight phenomenon detected in the first scan at $40-50^{\circ} \mathrm{C}$ (see Fig. $5 \mathrm{a}$ ), that could be associated with the $T_{\mathrm{g}}$ of separated amorphous MDI-BDO hard segments (or separated amorphous domains very rich in hard segments) also disappears in the second scan; this was then confirmed by DMA (see below).

Knowing that the value of $\mathrm{T}_{\mathrm{g}}$ globally reflects the degree of purity of the soft domains and/or the amount of dissolved $\mathrm{HS}^{[23]}$ several comparisons can be made. First when comparing 3 samples based on the same polyester diol but with increasing $\mathrm{HS} \%$, for almost every series $\mathrm{T}_{\mathrm{g}}$ regularly increases. This can be attributed to the presence of increasing amounts of dissolved MDI-BDO hard segments in the soft domains (for a pure MDI-BDO polyurethane with a high molar mass, $T_{g}=107^{\circ} \mathrm{C}$ ${ }^{[24]}$ ). The values of $T_{g}$ recorded during the second scans are usually in the same order as in the corresponding first scans.

For the TPUs derived from AA-diol-1 type polyester diols, the observed $\mathrm{T}_{\mathrm{g}}$ is about the same for BDO and MPDO-based macrodiols whereas it is slightly higher for the samples with a polyester based on HDO. The same holds for the $T_{g}$ recorded during the second scans, and suggests that the AA-HDO-1 polyester chain is slightly more miscible with the MDI-BDO hard segments than those based on the other 2 diols.

For the series of TPUs derived from MGA-diol-1 polyesters, almost the same conclusion can be drawn, except that the case of the MPDO-based sample is somewhat intermediate between BDO and HDO.

When comparing series based on an AA-diol-1 type macrodiol with the materials derived from the corresponding MGA-diol-1, slightly higher $T_{g} s$ seem to be found in the case of MGA, suggesting that the latter would slightly increase the miscibility with MDI-BDO hard segments. However this trend is rather subtle, and is not observed in the case of BDO-based polyesters.

Finally the comparison between samples based on AA-BDO-1 and -3, or between MGA-BDO-1 and -3 , clearly shows that the longer starting macrodiols lead to better phase-separated polyurethanes with a much lower $T_{g}$ of the soft domains, even in the second scan for which $T_{g}$ increases by about only $5^{\circ} \mathrm{C}$, i.e. much less than for the materials derived from shorter macrodiols. The immiscibility between soft and hard segments increases with their length. This was already observed in the past for other segmented polyurethanes. ${ }^{[25]}$ Moreover, in the case of AA-BDO-3, the 
soft chains of the macrodiol are sufficiently long to be able to partially crystallize within the TPU. For the samples derived from this particular diol a melting peak is clearly visible during the first heating scan in the range $36-43^{\circ} \mathrm{C}$ (see Figure 5). In addition the material with the highest content in soft domains, AA-BDO-3-30\%, even displays a crystallization followed by a melting peak during the second heating scan, denoting the strong tendency of the soft phase to crystallize for this particular formulation. For the other AA-BDO-3 samples though, the cooling rate is probably too high to allow this re-crystallization, especially as part of the hard segments remain dissolved in the soft phase as confirmed by the increase in $T_{g}$, and no melting of the soft phase can be observed in the $2^{\text {nd }}$ scan.

Apart from these transitions related to the soft phase, endothermic peaks are also detected at high temperature for all the materials and can be associated with the polyurethane hard domains. In the literature, segmented polyurethanes based on MDI-BDO hard segments have been widely studied, starting with the works of Cooper, ${ }^{[26-28]}$ or Koberstein ${ }^{[19,29,30]}$ and still very recently by Li. ${ }^{[1]}$ DSC annealing experiments were combined with WAXD, AFM, FTIR or more recently with movingwindow two-dimensional correlation spectroscopy to identify the observed transitions. Multiple endotherms detected at high temperatures, up to $250^{\circ} \mathrm{C}$, can be associated successively with the disruption of ordered microdomain structure at the micro-phase mixing transition (MMT), and for those at still higher temperatures to the melting of microcrystalline HS. From Koberstein's experiments, for all annealing conditions the disruption of the pseudo-ordered hard MDI-BDO microdomains precedes melting of the microcrystalline HS.

In this work, melting peaks were observed up to $224^{\circ} \mathrm{C}$ (for samples with $50 \mathrm{wt} \% \mathrm{HS}$ ) in the first scans (polymer annealed at $110^{\circ} \mathrm{C}$ ). Note that in the past, the presence of MDI-BDO spherulites melting at $224-226^{\circ} \mathrm{C}$ has been experimentally clearly evidenced in HS-rich segmented polyetherurethanes. ${ }^{[32]}$ However other authors associated this high melting peak with the solvent processing used for this particular sample preparation, ${ }^{[33]}$ but they nevertheless pointed out a melting endotherm around $215^{\circ} \mathrm{C}$ for analogous bulk-processed polyurethanes. ${ }^{[30]}$ Here within a series, samples with the highest $\mathrm{HS} \%$ also display endotherms at the highest temperature, denoting increasing amounts of better ordered hard domains. Moreover the comparison between corresponding polyurethanes derived either from diacid-BDO-1 or -3 macrodiols shows that those with the longest soft segments display the most highly ordered hard phase, with melting peaks at higher temperature and higher melting enthalpies, and consistently with a purer soft phase (see above). Quite logically, using a longer soft segment while keeping the same weight proportion of hard segments must induce higher average lengths for these HS as well; this can explain their higher degree of ordering. ${ }^{[25]}$ These samples definitely have a higher degree of microphase separation than those based on the shorter macrodiols.

In the second scans, the increase in the $T_{g}$ of the soft phase is logically accompanied by a decrease in the number of melting peaks of the hard domains and in their temperature.

\section{Thermal Stability}

The thermal stability of the prepared TPUs was assessed through TGA measurements performed in nitrogen and in air. Typical curves are displayed in the Supporting Information (Figure S1) and systematically show 2 main degradations at ca. $350^{\circ} \mathrm{C}$ and $420^{\circ} \mathrm{C}$. The values of $T_{d 5 \%}$ (listed in Table 4) are not influenced by the length of the polyol, yet slightly decrease when increasing the HS 
proportion; this seems rather logical since the thermally reversible urethane bonds should be the first to degrade when heating the material. ${ }^{[34-36]}$ The esters and other functions related to the soft segment are expected to degrade at higher temperature $\left(2^{\text {nd }}\right.$ peak on the derivative curves at $\approx$ $420^{\circ} \mathrm{C}$ that indeed increases with the relative amount of soft segment). Finally if $T_{d 5 \%}$ does not seem to depend on the nature of the diol used to synthesize the starting polyester macrodiol (BDO, HDO or MPDO), it is systematically slightly lower (by about $5-10^{\circ} \mathrm{C}$ ) for a sample based on MGA than for its counterpart derived from AA, at least in nitrogen. In air though, this discrepancy seems to fade.

\section{Dynamic Mechanical Behavior}

Samples were systematically analyzed from $-100^{\circ} \mathrm{C}$ to $150^{\circ} \mathrm{C}$ in tensile mode. Typical curves are depicted in Figure 6a-c. First, Figure 6a displays the thermomechanical behavior of sample MGAHDO-1 50\% that is representative of all the studied TPUs, i.e. elastomeric materials with a single principal mechanical relaxation that tends to broaden towards high temperatures. This main relaxation is associated with the glass transition of the soft domains, while the small shoulder around $50^{\circ} \mathrm{C}$ could be related to the glass transition of some separated amorphous hard domains, although this phenomenon is not always clearly visible in the DSC thermograms. As these hard segments begin to disorder and melt, the conservation modulus $\mathrm{E}^{\prime}$ finally initiates a sharp decrease above $150^{\circ} \mathrm{C}$.

In Figure 6b, $\mathrm{E}^{\prime}$ curves recorded for all the BDO-1 samples with varying $\mathrm{HS} \%$ and based on both diacids were superimposed; the same was done for $\tan \delta$ curves in Figure $6 \mathrm{c}$. Figure $6 \mathrm{~b}$ shows that very close thermomechanical behaviors are observed when comparing each AA-based sample with its MGA-based counterpart. For both diacids, the rubbery modulus is strongly dependent on the amount of hard segments ${ }^{[37]}$, in agreement with the fact that the latter act as physical crosslinks and reinforcing, covalently linked fillers. From the superimposition of $\tan \delta$ curves, other observations can be made (Figure 6c): first, low amounts of HS are associated with a high and narrow mechanical transition, whereas it becomes broader (especially towards high temperatures) and displays lower and lower amplitude as HS\% increases. This phenomenon can be related to the increase in the elastic modulus with increasing amounts of hard segments, and reflects the associated decrease in mobility of the soft segments as their moves are hampered by more and more physical crosslinks. For a given $\mathrm{HS} \%$, this amplitude is almost equal for the AA- and the MGA- based sample. However the temperature at the relaxation maximum is slightly higher for the MGA-based polyurethane, which might indicate a slightly higher miscibility between soft and hard segments in this case. 

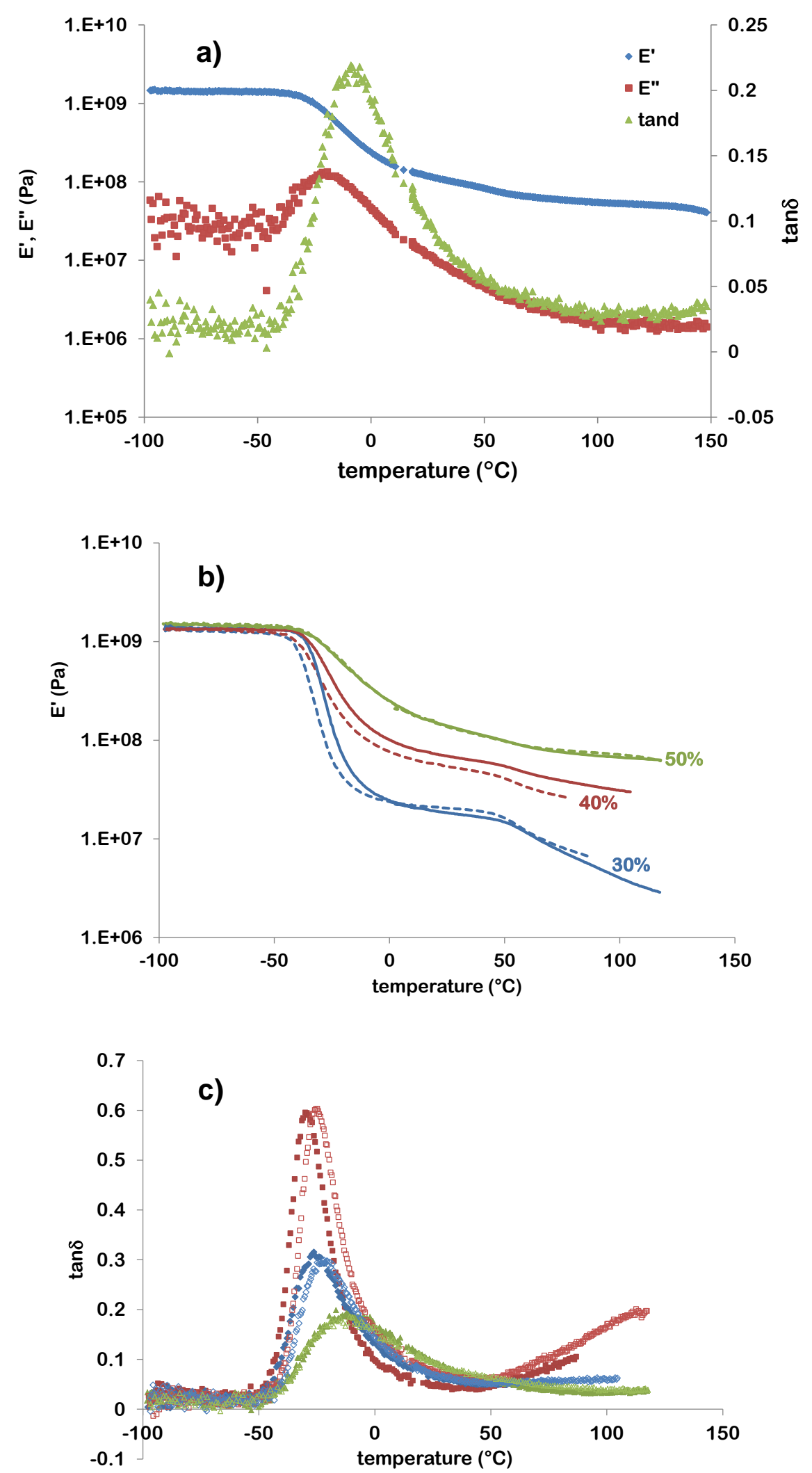

Figure 6. Dynamic mechanical analysis of segmented PU samples: a) $E^{\prime}, E^{\prime \prime}$ and tan $\delta$ curves recorded for MGA-HDO-1 50\%; b) E' curves for BDO-1 series with various HS \% : AA (- - -); MGA(-); c) $\tan \delta$ curves for $B D O-1$ series : $\square: A A, 30 \%$; $: A A, 40 \% ; \triangle: A A, 50 \% ; \square: M G A, 30 \% ; \diamond: M G A$, 40\%; $\triangle$ :MGA, $50 \%$ 


\section{Hardness}

Table 4 shows that the values of Shore A hardness measured at room temperature for AA- or MGA-based samples are systematically remarkably close for a given composition, with one exception. Very generally the observed Shore A hardness increases when increasing the weight proportion of hard segments HS\%, consistently with the elastic moduli of these materials (Figure 6b). Samples of the BDO-3 series, i.e. those based on the longer soft segments, indeed display different tendencies. More precisely in this case, whereas the MGA-based samples still show a regularly increasing hardness from 30 to $50 \%$ HS, the 3 AA-based polyurethanes show the same, high Shore hardness ( 95 ShA) for all the HS\% values. This simply reflects the fact that in this case the soft segment is long enough to be able to crystallize, as revealed by the additional melting observed around $35-40^{\circ} \mathrm{C}$ by DSC (see Table 4 and Figure $5 \mathrm{~b}$ ), and contrary to the MGA-based polyester. This is thus once again a real advantage of MGA, which allows the preparation of elastomers with adjustable hardness over a wider range of composition, i.e. over a wider range of mechanical characteristics at high temperature.

\section{Tensile Testing}

The mechanical behavior of the TPUs was finally evaluated by tensile tests on specimens cut from plates. Representative stress-strain curves are shown in Figure 7a to c, for all the samples based on macrodiols with $M_{n} \approx 1000 \mathrm{~g} \cdot \mathrm{mol}^{-1}$. It appears that in the first 150-200\% elongation, the curves associated with each AA-based sample and with its MGA-based counterpart are more or less superimposed. Beyond this elongation, 2 situations are encountered: for samples derived from BDO or HDO, MGA-based samples keep on elongating whereas AA-samples display a strong strain hardening attributed to the partial crystallization of the soft segments. This results in much higher ultimate elongations for the TPUs prepared from MGA-based macrodiols, compared to AA-based samples. In contrast, samples based on "MPDO" (that did not display any crystallinity in their DSC curves) are not prone to strain hardening, and even those derived from AA show a purely elastomeric behavior. In this case it is very difficult to differentiate AA- and MGA-based materials.

For all the studied series, the values of Young moduli E evaluated for AA-based samples and for their MGA-based counterpart are identical (see Fig.S7 in Supplementary Material). Other parameters have to be considered in order to be able to differentiate both TPU families. In this respect, the ultimate stress $\sigma_{\mathrm{B}}$ and elongation at break $\varepsilon_{\mathrm{B}}$ can be plotted vs the amount of hard segments for all series. This was done in Figure $8 \& 9$. It appears first that for both starting diacids, $\sigma_{B}$ increases regularly with HS\%. The observed values are higher for AA-based samples when the starting diol is BDO, whereas they become more comparable for both acids in the case of HDO and almost identical in the case of "MPDO"; this is consistent with the strain hardening phenomenon reported above for the crystallizable materials. 

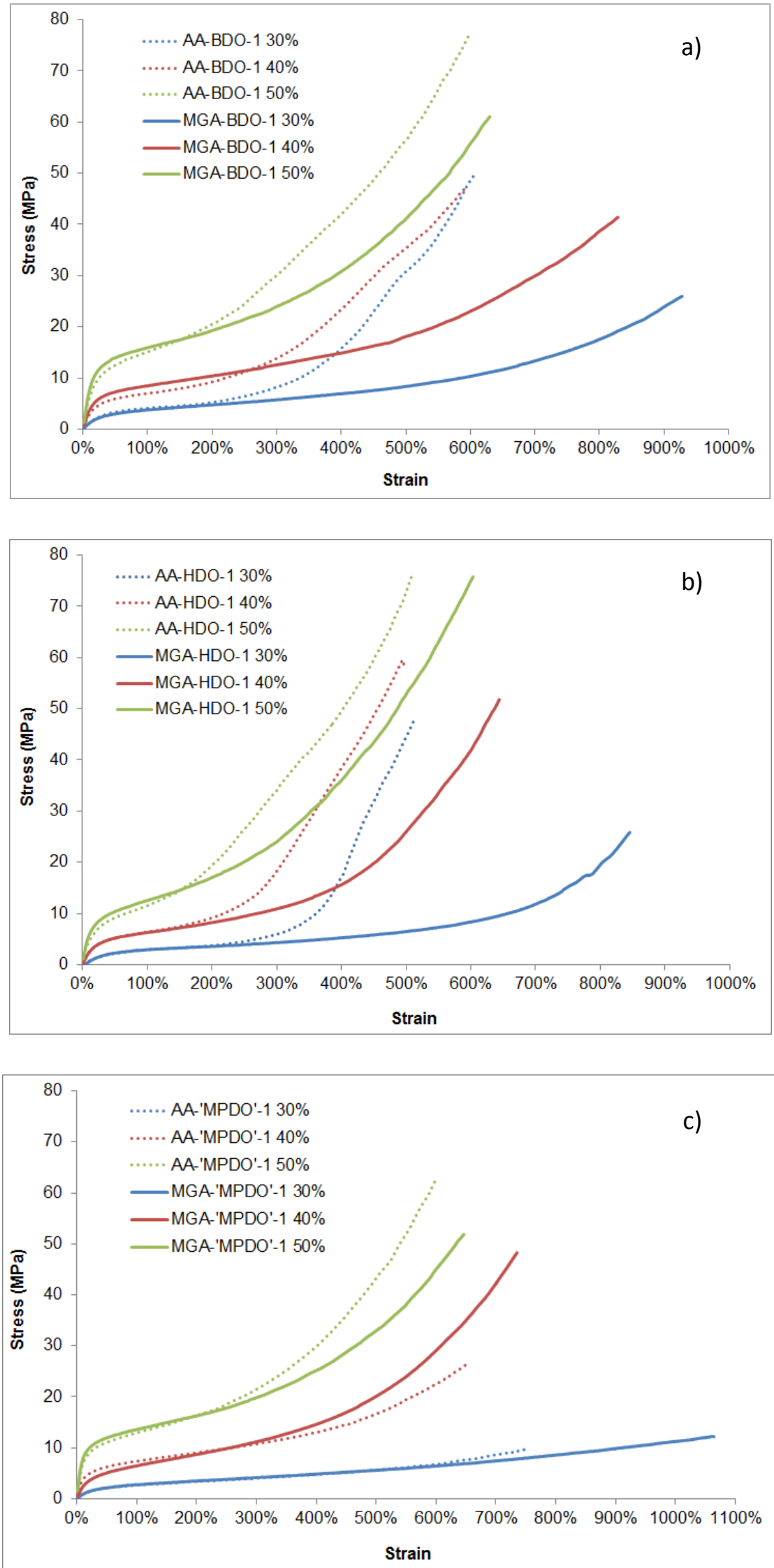

Figure 7. Stress-strain curves for TPU series based on various macrodiols with $M \approx 1000$ g. $\mathrm{mol}^{-1}$; (a) starting diol: BDO; (b) starting diol: HDO; (c) starting diol: "MPDO" 


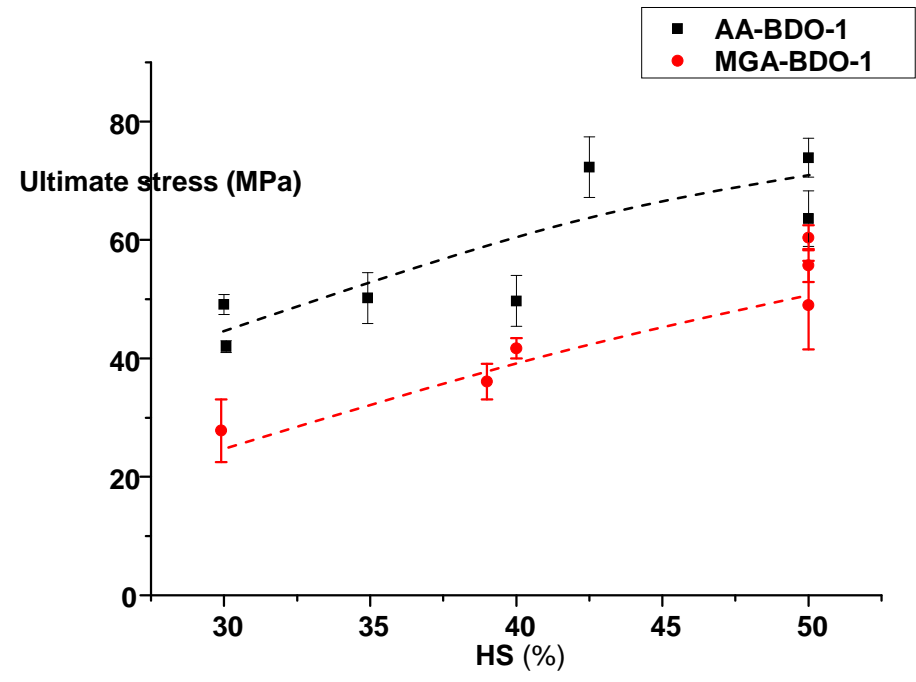

a)

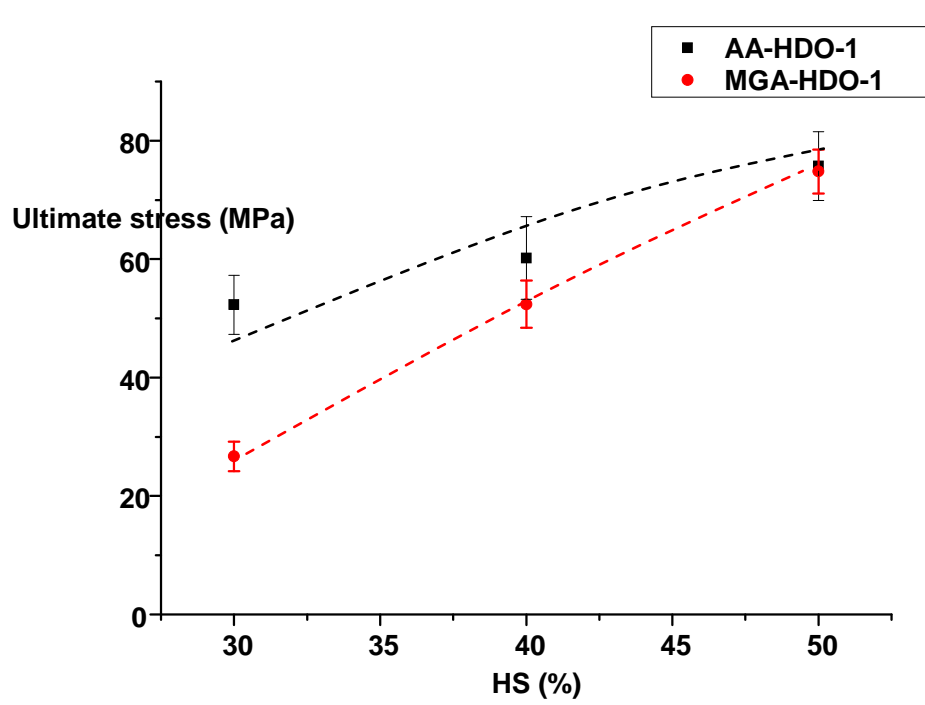

b)

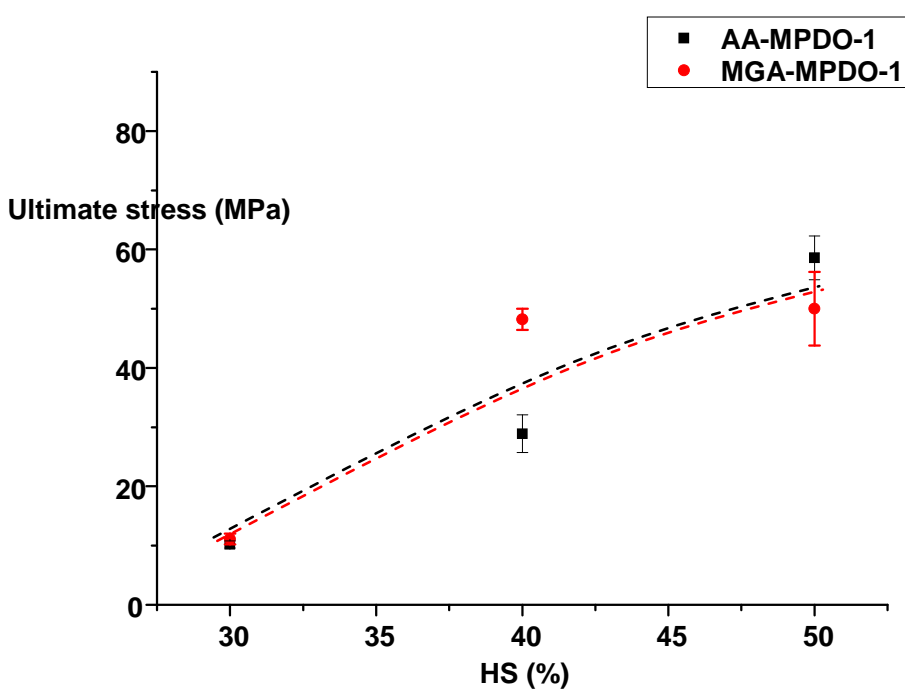

c)

Figure 8. Evolution of the ultimate stress of the prepared TPUs with the HS content; (a) starting diol: BDO; (b) starting diol: HDO; (c) starting diol: "MPDO" 

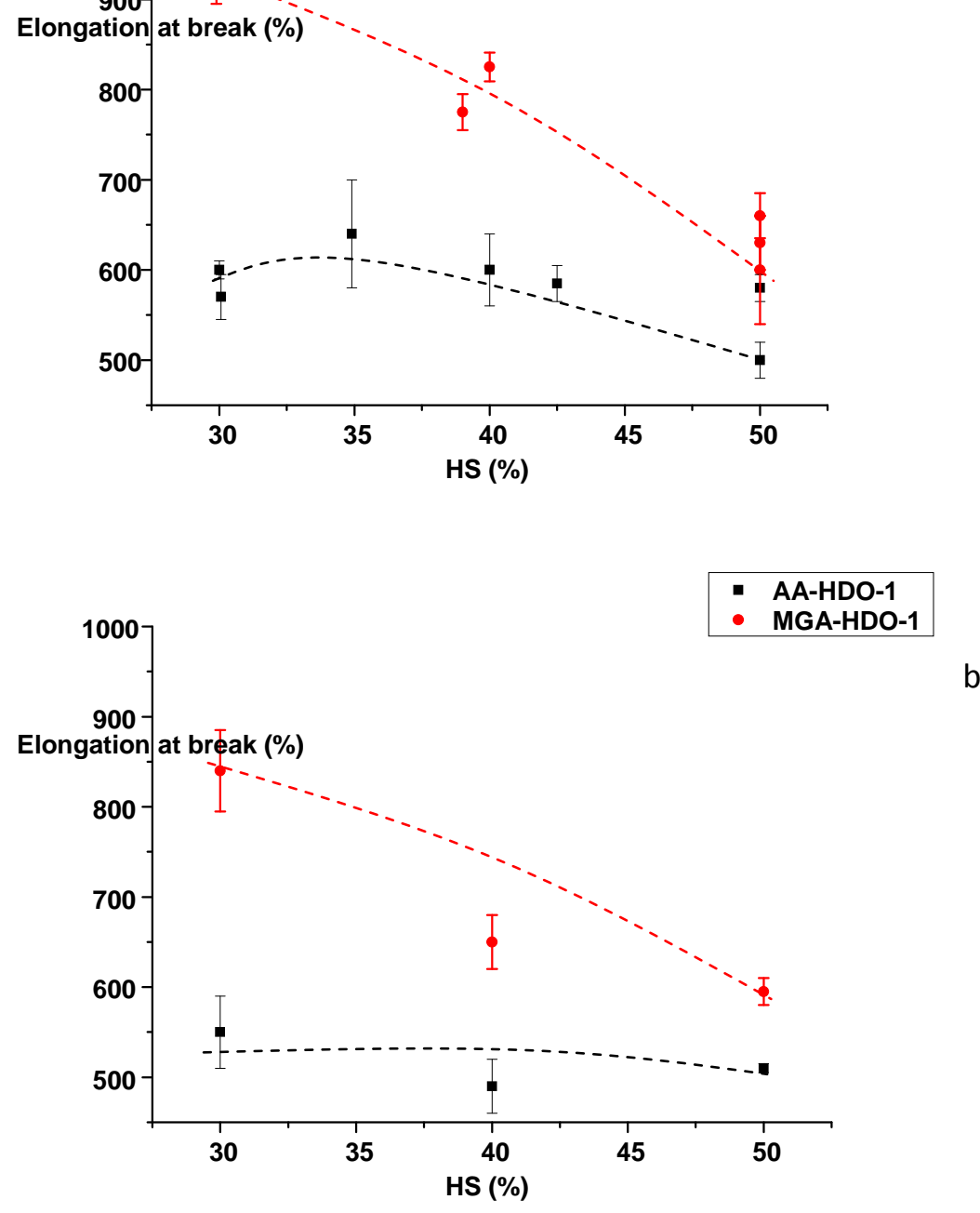

b)

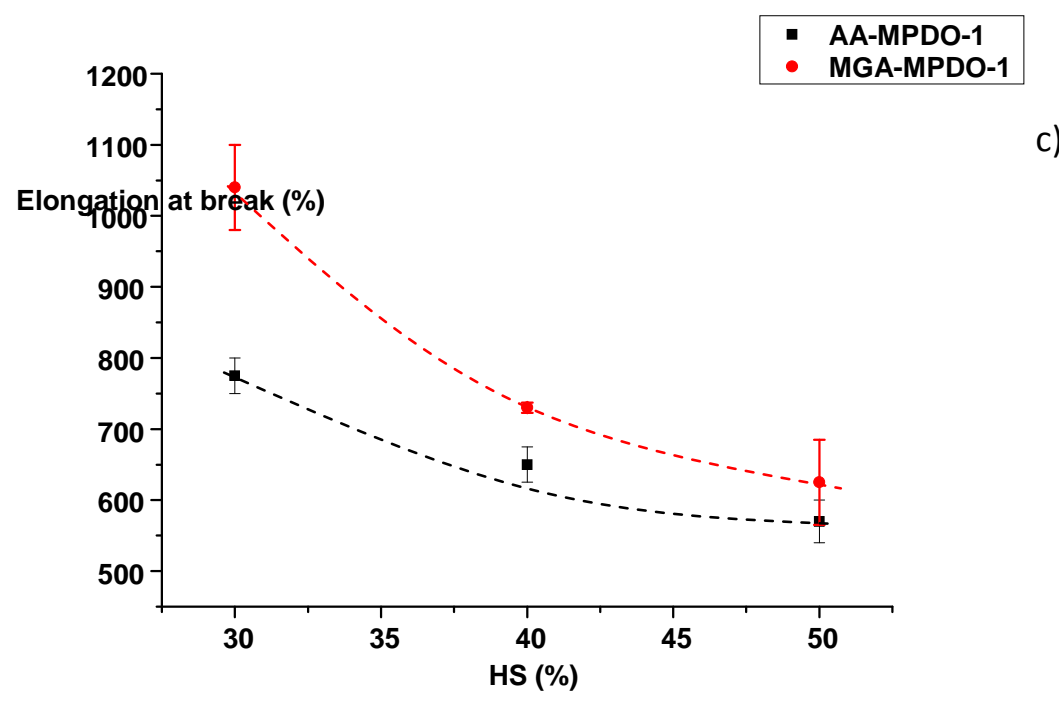

Figure 9. Evolution of the elongation at break of the prepared TPUs with the HS content; (a) starting diol: BDO; (b) starting diol: HDO; (c) starting diol: "MPDO" 
In contrast, the elongation at break $\varepsilon_{B}$ is systematically higher for TPUs derived from MGA, as opposed to AA (see Figure 9). This was also observed on high-molar mass thermoplastic MGA-based vs $A A$-based polyesters. ${ }^{[16]}$ Quite logically here, this parameter regularly decreases when increasing $\mathrm{HS} \%$, since more and more physical crosslinks due to hydrogen bonding between hard segments are present in the materials, and both curves even tend to merge as the composition gets closer to that associated with phase inversion between soft and hard phases. ${ }^{[38]}$ But the phenomenon is particularly marked for softer samples with lower amounts of hard segments, and constitutes a real advantage for MGA-derived samples over the classical materials obtained from AA-based polyester polyols, since all the other mechanical characteristics are comparable.

Finally samples with $40 \mathrm{wt} \% \mathrm{HS}$ were subjected to 10 consecutive tensile cycles (no delay between cycles) with variable maximal strain $(100,400$ or $800 \%)$ at $50 \mathrm{~mm} / \mathrm{min}$. Typical curves recorded for MGA-BDO-1 40\% are displayed in Figure 10a. During the first loading stage, all curves superimpose on a single "master curve". After unloading and once the stress value reaches zero, a residual strain is observed that increases with the maximum strain or with the number of cycles. This residual strain reflects the partially viscoplastic character of the studied materials. Some stress softening is also observed, with the stress at the maximum strain regularly decreasing as the number of cycles increases ("Mullins effect, see also below). ${ }^{[39]}$ In the literature, and following the pioneering work from Kilian et $\mathrm{al}^{[40]}$ such phenomena were attributed to a change in the polyurethane microstructure occurring during the first loading cycle (often named "conditioning cycle" ${ }^{[41]}$ ): some hard segments are assumed to be expelled from the hard domains, reducing their volume fraction and increasing that of the soft phase. ${ }^{[39]}$ The new soft phase coupled with the remaining hard domains can be seen as a more compliant material dominating the following deformations. ${ }^{[42]}$ Note that the strain hardening phenomenon observed for AA-based samples is clearly highlighted when comparing the first load-unload cycles for the various elastomers (see Fig. S8 in Supplementary Material), above ca. $300 \%$ strain. 


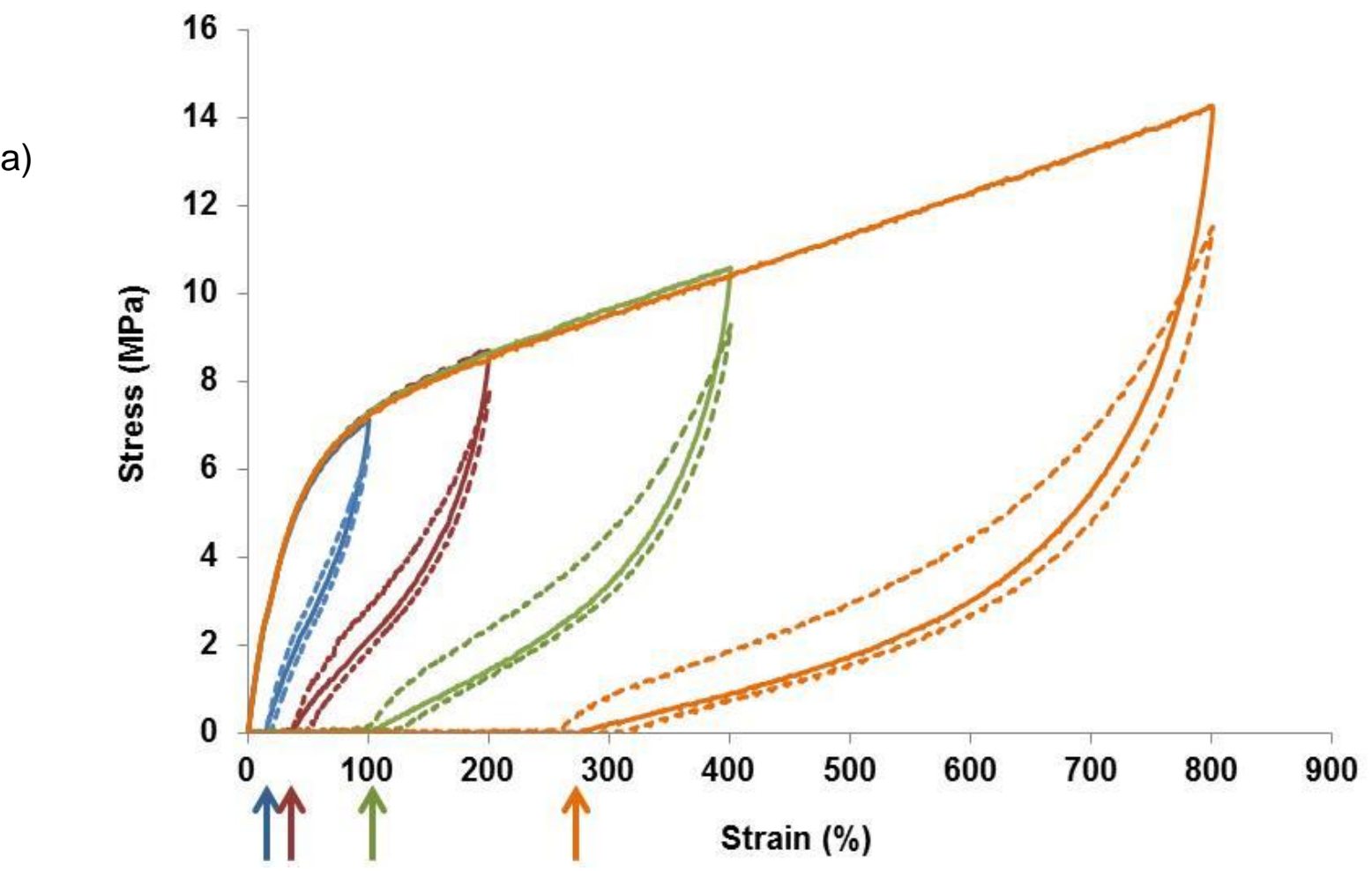

b)

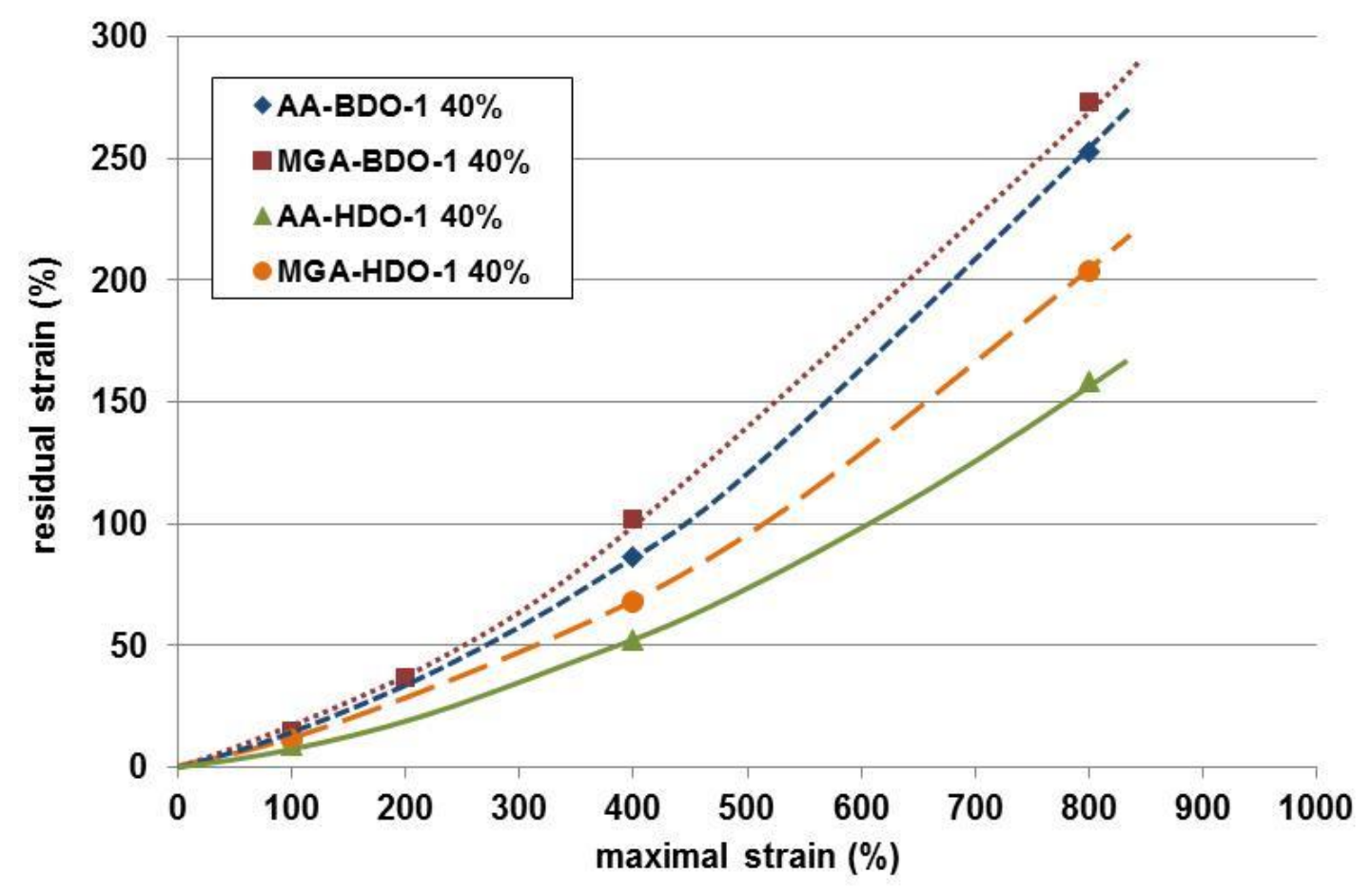

Figure 10. (a) Example of stress-strain curves and hysteresis observed for the sample MGABDO-1 40\% subjected to various maximal strains $(100,200,400$ or $800 \%)$ at $50 \mathrm{~mm} / \mathrm{min}$; (-) : first cycle, (- - ): $10^{\text {th }}$ cycle; (b) residual strain (arrows in the $1^{\text {st }}$ graph) observed after the $1^{\text {st }}$ cycle for various formulations (40\% HS) 


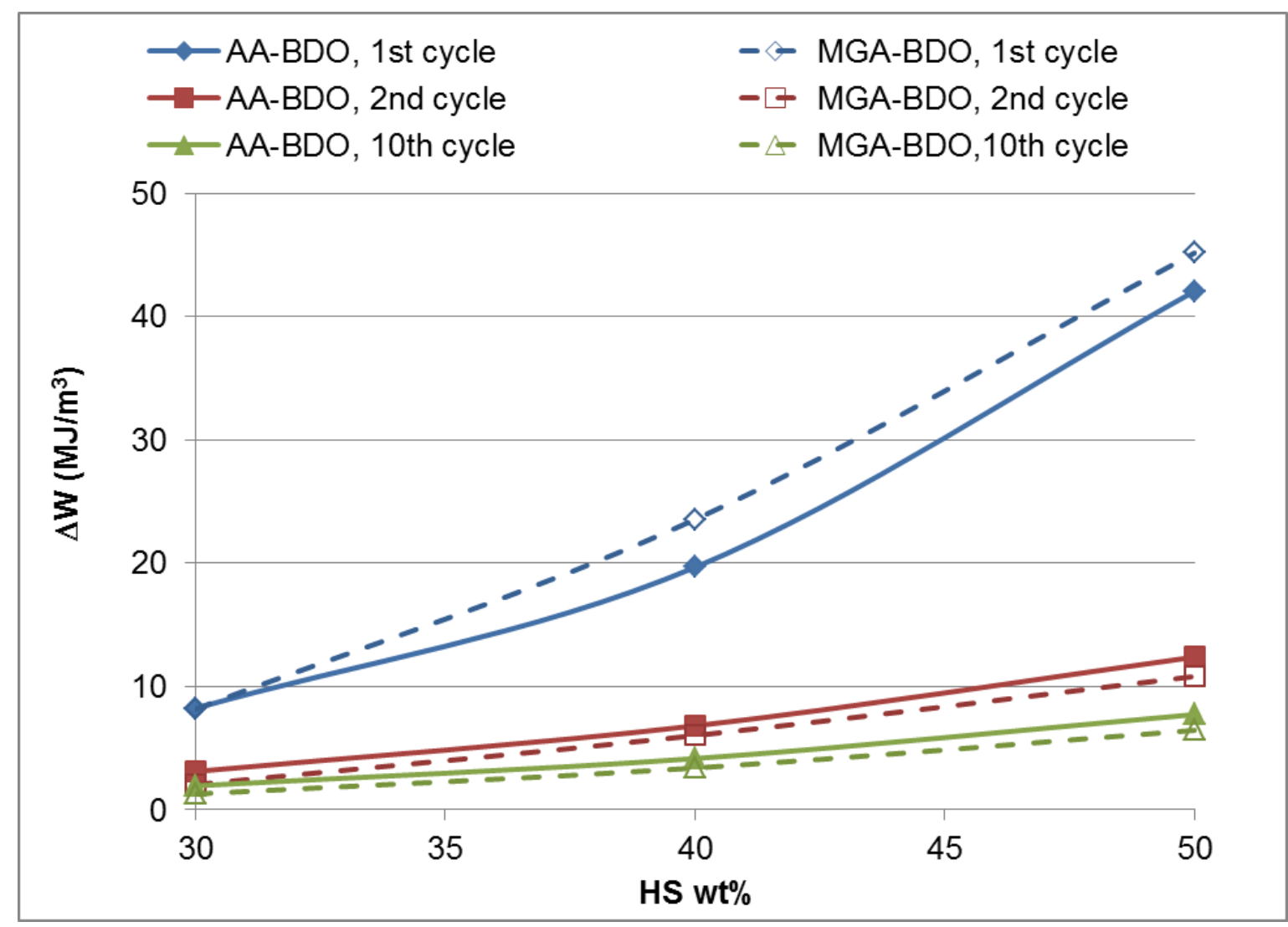

Figure 11. Energy of the elastic hysteresis obtained for various AA-BDO-1 and MGA-BDO-1 based polyurethanes undergoing tensile load-unload cycles with maximal nominal strain $400 \%$.

Figure $10 \mathrm{~b}$ shows the values of residual strain measured after the $1^{\text {st }}$ cycle (exactly the same tendency is observed after 10 cycles) for several formulations based either on AA or MGA. Two main features can be deduced from this figure: first, samples based on MGA show a slightly higher residual strain compared to their AA-based counterpart; this is apparently not due to the molar masses that are all comparable; all 4 samples also have about the same hardness (from 79 to 82 ShA). -Then, samples based on HDO-polyester polyols clearly display lower residual strains. The main difference deduced from previous experiments was that these samples had a lower degree of microphase separation compared to those based on BDO-polyester polyols. Referring to the above explanations for stress softening and residual strain, in the case of this less-separated material more HS are already present in the soft phase before the $1^{\text {st }}$ loading cycle, and consequently maybe a lower proportion can be expelled from the hard phase to the soft phase during this $1^{\text {st }}$ cycle. Therefore the structure of the material would not change as much between the $1^{\text {st }}$ and $2^{\text {nd }}$ loading cycle. This is consistent with the fact that while the first loading curves are quite different between BDO-polyester polyol and HDO-polyester polyol based polyurethanes (HDO curve lower), there is almost no difference between them for the following loading cycles. Both types of material would thus be brought to a rather similar microstructure by their first tensile loading.

Work imputs and hystereses were also evaluated for all the tested samples (see Table 5). For example Figure 11 shows the comparison for a series of samples based on MGA-BDO and AA-BDO macrodiols tested to a maximal nominal strain $400 \%$. Several key features can be pointed out. 
First, the classical Mullins effect ${ }^{[42,43]}$ is clearly evidenced for all the samples, with an important decrease in the cycle hysteresis due to the stress softening phenomenon between the first and second loading cycles. This is attributed to some restructuring with irreversible deformation of the hard segments accompanying the stretching of the soft segments ${ }^{[41]}$. For all the studied samples, the dissipated work keeps decreasing slightly during the following cycles and finally stabilizes (see Fig. S9 in Supplementary Material).

Then, the dissipated work logically increases with the amount of hard segments, in agreement with the literature ${ }^{[41]}$. The phenomenon is quite clear for the first cycle, whereas it is less pronounced for the following cycles that do not induce significant additional restructuring of the hard segments.

Finally, the energy hysteresis during the first cycle is systematically higher for the MGA-based samples than for their AA-based counterpart. However the order is often reversed for all the following cycles, starting from the second cycle. As both series are made of similar hard segments, this could be related to the interactions between soft and hard domains which could be initially higher for the MGA series; in this respect the stretching of the soft segments would induce more deformation and breakup of the hard domains during the "conditioning cycle"[41].

\section{CONCLUSIONS}

MGA, a new diacid and abundant indirect product of the polyamide industry, was reacted with several diols to prepare series of new polyester polyols with adjustable molar masses. These polyols were then considered as innovative precursors for segmented polyurethanes. From the comparison with analogous hydroxylated oligomers or polyurethane materials based on adipic acid instead of MGA, several benefits can be attributed to the MGA derivatives. First concerning the starting polyols, MGA-based compounds turned out to be systematically amorphous, unlike polyadipates that are often semi-crystalline and therefore need to be heated to be processed; MGA derivatives also show a lower viscosity than their polyadipate counterpart with the same molar mass and thus can be considered more easily processable in the manufacture of segmented polyurethanes, especially by casting.

Segmented polyurethanes with varying hard segment content were then obtained from analogous series of AA- and MGA-based polyester polyols with different compositions or lengths, after bulk polyaddition with MDI and 1,4-butanediol. For all these formulations, elastomers with high molar masses were always obtained and could be rather easily processed in the form of homogeneous plates. Even after reaction, once again AA-based soft segments retained their tendency to crystallize within the polyurethane material, either spontaneously (longer macrodiols) or when submitted to a mechanical stress (strain hardening), while segmented polyurethanes derived from MGA-polyester polyols always showed perfectly amorphous soft domains. Therefore although most of the prepared materials were finally equivalent between MGA and adipic acid derivatives, the MGA-based TPUs generally displayed a more adjustable hardness, together with a much higher elongation at break. 


\section{ACKNOWLEDGEMENTS}

The authors thank the NMR Polymer Center of the "Institut de Chimie de Lyon" (FR3023), for assistance and access to the NMR facilities.

\section{REFERENCES AND NOTES}

1. Petrovic, Z.S. Polym. Rev. 2008, 48, 109-155.

2. Pfister D.P.; Xia, Y.; Larock, R.C. ChemSusChem 2011, 4, 703-717.

3. Babb, D.A. Adv. Polym. Sci. 2012, 245, 315-360.

4. Desroches, M.; Escouvois, M.; Auvergne, R.; Caillol, S.; Boutevin, B. Polym. Rev. 2012, 52, 3879.

5. Datta, J.; Głowińska, E. J. Elastom. Plast. 2014, 46, 33-42.

6. Xu, Y.; Petrovic, Z.; Das, S.; Wilkes, G.L. Polymer 2008, 49, 4248-4258.

7. Sonnenschein, M.F.; Ginzburg, V.V.; Schiller, K.S.; Wendt, B.L. Polymer 2013, 54, 1350-1360.

8. Sonnenschein, M.F.; S Guillaudeu, S.J.; Landes, B.G.; Wendt, B.L. Polymer 2010, 51, 36853692.

9. Polen T.; Spelberg, M.; Bott, M. J. Biotechnol. 2013, 167, 75-84.

10. Buisine, O.; Leconte, P.; Agati , M. (Rhodia Operations), US Patent 8263 804, 2012.

11. Jacquot, R.; Rhers, B. (Rhodia Operations), World Patent WO 2014/012754, 2014.

12. Streu, J.; Marx, M.; Weyland, P.; Scherzer, D.; Straehle , W. (BASF), US Patent 4778 830, 1988.

13. Furukawa, M. J. Appl. Polym. Sci. Appl. Polym. Symp. 1994, 53, 61-76.

14. Murata, S.; Nakajima, T.; Tsuzaki, N.; Yasuda, M.; Kato, T. Polym. Degrad. Stabil. 1998, 61, 527-534.

15. Furukawa, M.; Shiiba, T.; Murata, S. Polymer 1999, 40, 1791-1798.

16. Milizia, T.; Vallero, R. (Novamont), World Patent WO2013/153147, 2013.

17. Wei, Y.; Jia, X.; Jin, D.; Davis, F.A.; Starner, W.E. Macromol. Rapid Commun. 1996, 17, 897903.

18. Chen, A.L.; Wei, K.L.; Jeng,R.J.; Lin, J.J.; Dai, S.A. Macromolecules 2011, 44, 46-59.

19. Koberstein, J.T.; Russell, T.P. Macromolecules 1986, 19, 714-720.

20. Macosko, C.W. Fundamentals of reaction injection molding, Hanser, New York, 1989.

21. Saiani, A.; Daunch, W.A.; Verbeke, H.; Leenslag, J.W.; Higgins, J.S. Macromolecules 2001, 34, 9059-9068.

22. Saiani, A.; Rochas, C.; Eeckhaut, G.; Daunch, W.A.; Leenslag, J.W.; Higgins, J.S. Macromolecules 2004, 37, 1411-1421.

23. Camberlin, Y.; Pascault, J.P. J. Polym. Sci.: Polym. Chem. Ed. 1983, 21, 415-423. 
24. Cuvé, L.; Pascault, J.P.; Boiteux, G.; Seytre, G. Polymer 1991, 32, 343-352.

25. Martin, D.J.; Meijs, G.F.; Renwick, G.M.; McCarthy, S.J.; Gunatillake, P.A. J. Appl. Polym. Sci. 1996, 62, 1377-1386.

26. Seymour, R.W.; Cooper, S.L. Macromolecules 1973, 6, 48-53.

27. Hesketh, T.R.; Van Bogart, J.W.C.; Cooper, S.L. Polym. Eng. Sci. 1980, 20, 190-197.

28. Van Bogart, J.W.C.; Bluemke, D.A.; Cooper, S.L. Polymer 1981, 22, 1428-1438.

29. Koberstein, J.T.; Galambos, A.F. Macromolecules 1992, 25, 5618-5624.

30. Leung, L.M.; Koberstein, J.T. Macromolecules 1986, 19, 706-713.

31. Li, C.; Liu, J.; Li, J.; Shen, F.; Huang, Q.; Xu, H. Polymer 2012, 53, 5423-5435.

32. Briber, R.M.; Thomas, E.L. J. Macromol. Sci. - Phys. 1983, B22, 509-528.

33. Leung, L.M.; Koberstein, J.T. J. Polym. Sci.: Polym. Phys. Ed. 1985, 23, 1883-1913.

34. Petrovic, Z.S.; Zavargo, Z.; Flynn, J.H.; McKnight, W.J. J. Appl. Polym. Sci. 1994, 51, 1087-1095.

35. Agić, A.; Bajsić, E.G. J. Appl. Polym. Sci. 2007, 103, 764-772.

36. Cervantes-Uc, J.M.; Moo Espinosa, J.I.; Cauich-Rodríguez, J.V.; Ávila-Ortega, A.; VázquezTorres, H.; Marcos-Fernández, A.; San Román, J. Polym. Degrad. Stabil. 2009, 94, 1666-1677.

37. Datta, J. J. Elastom. Plast. 2010, 42, 117-127.

38. Qi, H.J.; Boyce, M.C. Mech. Mater. 2005, 37, 817-839.

39. Bartolomé, L.; Aurrekoetxea, J.; Urchegui, M.A.; Tato, W. Mater. Design 2013, 49, 974-980.

40. Enderle, H.F.; Kilian, H.G.; Heise, B.; Mayer, J.; Hespe, H. Colloid Polym. Sci. 1986, 264, 305322.

41. Christenson, E.M.; Anderson, J.M.; Hiltner, A.; Baer, E. Polymer 2005, 46, 11744-11754.

42. Buckley, C.P.; Prisacariu, C.; Martin, C. Polymer 2010, 51, 3213-3224.

43. Marckmann, G.; Verron, E.; Gornet, L.; Chagnon, G.; Charrier, P.; Fort, P. J. Mech. Phys. Solids 2002, 50, 2011-2028.

44. Ahn, B.D.; Kim, S.H.; Kim, Y.H.; Yang, J.S. J. Appl. Polym. Sci. 2001, 82, 2808-2826.

45. Aylwin, P.A.; Boyd, R.H. Polymer 1984, 25, 323-329. 


\section{FIGURE CAPTIONS}

FIGURE $1:{ }^{1} \mathrm{H}$ NMR spectrum of sample MGA-BDO-1 $\left(23^{\circ} \mathrm{C}, \mathrm{CDCl}_{3}, 250 \mathrm{MHz}\right)$

FIGURE 2 : Thermogravimetric analysis of the prepared polyols $\left(10^{\circ} \mathrm{C} / \mathrm{min}\right.$, air $)$

FIGURE 3 : Viscosities of the prepared polyester polyols at a) $50^{\circ} \mathrm{C}$; b) $80^{\circ} \mathrm{C}$

FIGURE 4 : Evolution of the NCO \% $(\diamond)$ and of the corresponding NCO conversion ( $\square$ ) during the addition reaction between MDI and MGA-BDO-2 at $80^{\circ} \mathrm{C}$ under nitrogen $\left([\mathrm{NCO}]_{0} /[\mathrm{OH}]_{0}=4.15\right.$, i.e. expected final conversion $=24 \%$ ).

FIGURE 5 : Typical DSC thermograms obtained for a) the MGA-BDO-1 series; b) the AA-BDO-3 series

FIGURE 6 : Dynamic mechanical analysis of segmented PU samples: a) $E^{\prime}, E^{\prime \prime}$ and $\tan \delta$ curves recorded for MGA-HDO-1 50\%; b) E' curves for BDO-1 series with various HS \% : AA (- - -); MGA(-); c) $\tan \delta$ curves for BDO-1 series : $\square$ : AA, 30\%; $\diamond$ : AA, 40\%; $\triangle$ : AA, 50\%; $\square:$ MGA, 30\%; $\diamond:$ MGA, 40\%; $\triangle$ : MGA, $50 \%$

FIGURE 7 : Stress-strain curves for TPU series based on various macrodiols with $\mathrm{M} \approx 1000 \mathrm{~g}$. $\mathrm{mol}^{-1}$; (a) starting diol: BDO; (b) starting diol: HDO; (c) starting diol: "MPDO"

FIGURE 8 : Evolution of the ultimate stress of the prepared TPUs with the HS content; (a) starting diol: BDO; (b) starting diol: HDO; (c) starting diol: "MPDO"

FIGURE 9 : Evolution of the elongation at break of the prepared TPUs with the HS content; (a) starting diol: BDO; (b) starting diol: HDO; (c) starting diol: "MPDO"

FIGURE 10 : (a) Example of stress-strain curves and hystereses observed for the sample MGA-BDO-1 $40 \%$ subjected to various maximal strains $(100,400$ or $800 \%)$ at $50 \mathrm{~mm} / \mathrm{min}$; (-) : first cycle, (....): $10^{\text {th }}$ cycle; (b) residual strain (arrows in the $1^{\text {st }}$ graph) observed after the $1^{\text {st }}$ cycle for various formulations ( $40 \% \mathrm{HS})$

FIGURE 11 : Energy of the elastic hysteresis obtained for various AA-BDO-1 and MGA-BDO-1 based polyurethanes undergoing tensile load-unload cycles with maximal nominal strain $400 \%$.

SCHEME 1 : Constituents of Rhodiacid ${ }^{\text {TM }}$-MGA 
Table 1. Main characteristics of the polyester polyols determined from ${ }^{1} \mathrm{H} N M R$ and chemical titration

\begin{tabular}{|c|c|c|c|c|c|c|c|c|c|c|c|c|}
\hline diol & \multicolumn{4}{|c|}{ BDO-based polyesters } & \multicolumn{4}{|c|}{ HDO-based polyesters } & \multicolumn{4}{|c|}{ MPDO-based polyesters } \\
\hline sample & $\begin{array}{c}\text { AA-BDO- } \\
1\end{array}$ & $\begin{array}{c}\text { AA-BDO- } \\
3\end{array}$ & $\begin{array}{l}\text { MGA- } \\
\text { BDO-1 }\end{array}$ & $\begin{array}{l}\text { MGA- } \\
\text { BDO-3 }\end{array}$ & $\begin{array}{c}\text { AA- } \\
\text { HDO-1 }\end{array}$ & $\begin{array}{c}\text { AA- } \\
\text { HDO-2 }\end{array}$ & $\begin{array}{l}\text { MGA- } \\
\text { HDO-1 }\end{array}$ & $\begin{array}{l}\text { MGA- } \\
\text { HDO-2 }\end{array}$ & $\begin{array}{c}\text { AA- } \\
\text { MPDO-1 }\end{array}$ & $\begin{array}{c}\text { AA- } \\
\text { MPDO-2 }\end{array}$ & $\begin{array}{l}\text { MGA- } \\
\text { MPDO-1 }\end{array}$ & $\begin{array}{c}\text { MGA- } \\
\text { MPDO-2 }\end{array}$ \\
\hline Water wt\% ${ }^{\text {a) }}$ & 0.28 & ND & 0.07 & ND & ND & ND & ND & ND & 0.03 & 0.02 & 0.01 & 0.01 \\
\hline $\mathrm{I}_{\mathrm{COOH}}(\mathrm{mg} \mathrm{KOH} / \mathrm{g})$ & 3.6 & 2.6 & 5.6 & 3.3 & 0.6 & 2.4 & 1.9 & 2.8 & 2.6 & 3.1 & 3.3 & 3.8 \\
\hline $\mathrm{DP}_{\mathrm{n}}$ & 15.4 & 39.3 & 17.1 & 27.8 & 10.2 & 20.1 & 9.6 & 18.1 & 14.4 & 22.4 & 14.5 & 26.5 \\
\hline$M_{\text {constitutive unit }}$ & \multicolumn{4}{|c|}{100.13} & \multicolumn{4}{|c|}{132.16} & \multicolumn{4}{|c|}{132.16} \\
\hline$M_{n}$ from $N M R$ & 1530 & 3925 & 1700 & 2770 & 1330 & 2640 & 1255 & 2370 & 1890 & 2950 & 1900 & 3490 \\
\hline $\mathrm{i}_{\mathrm{OH}}(\mathrm{mg} \mathrm{KOH} / \mathrm{g})$ & 86.4 & 29.0 & 74.5 & 39.2 & 95.9 & 48.0 & 96.5 & 52.1 & 61.4 & ND* & 63.0 & ND \\
\hline$M_{n}$ from titration & 1250 & 3550 & 1400 & 2640 & 1160 & 2230 & 1140 & 2040 & 1750 & ND & 1690 & ND \\
\hline \%OH chain ends & 96.0 & 91.8 & 93.0 & 92.2 & 99.4 & 95.2 & 98.1 & 94.9 & 95.9 & ND & 95.0 & ND \\
\hline$\% \mathrm{COOH}$ chain ends & 4.0 & 8.2 & 7.0 & 7.8 & 0.6 & 4.8 & 1.9 & 5.1 & 4.1 & ND & 5.0 & ND \\
\hline$P \max$ for a $1 / 2 / 1 \mathrm{TPU}$ & 97 & 46 & 54 & 49 & 640 & 81 & 204 & 75 & 94 & ND & 76 & ND \\
\hline$M_{n}$ from $S E C^{b)}$ & $2700^{c)}$ & $7300^{d)}$ & $2300^{c)}$ & $3700^{d)}$ & & & $2200^{d)}$ & & & & & \\
\hline
\end{tabular}

* ND: not determined

a) Karl Fischer determination

b) conventional calibration according to polystyrene standards

c) in THF

d) In DMF/LiBr 
Table 2. Thermal characteristics of the synthesized polyester polyols

\begin{tabular}{|c|c|c|c|c|c|c|c|c|c|c|c|c|}
\hline diol & \multicolumn{4}{|c|}{ BDO-based polyesters } & \multicolumn{4}{|c|}{ HDO-based polyesters } & \multicolumn{4}{|c|}{ MPDO-based polyesters } \\
\hline sample & $\begin{array}{c}\text { AA-BDO- } \\
1\end{array}$ & $\begin{array}{c}\text { AA-BDO- } \\
3\end{array}$ & $\begin{array}{l}\text { MGA- } \\
\text { BDO-1 }\end{array}$ & $\begin{array}{l}\text { MGA- } \\
\text { BDO-3 }\end{array}$ & $\begin{array}{c}\text { AA-HDO- } \\
1\end{array}$ & $\begin{array}{c}\text { AA-HDO- } \\
2\end{array}$ & $\begin{array}{l}\text { MGA- } \\
\text { HDO-1 }\end{array}$ & $\begin{array}{l}\text { MGA- } \\
\text { HDO-2 }\end{array}$ & $\begin{array}{c}\text { AA- } \\
\text { MPDO-1 }\end{array}$ & $\begin{array}{c}\text { AA- } \\
\text { MPDO-2 }\end{array}$ & $\begin{array}{l}\text { MGA- } \\
\text { MPDO-1 }\end{array}$ & $\begin{array}{l}\text { MGA- } \\
\text { MPDO-2 }\end{array}$ \\
\hline $\mathrm{T}_{\mathrm{g}}\left({ }^{\circ} \mathrm{C}\right)^{\mathrm{a}}$ & -71 & $-60^{b}$ & -63 & -58 & $?^{b}$ & $-60^{b}$ & -70 & -66 & -65.5 & -63 & -60 & -56 \\
\hline $\mathrm{T}_{\mathrm{m} 1}\left({ }^{\circ} \mathrm{C}\right)^{\mathrm{c}}$ & 50 & 54.5 & / & / & 50 & 55 & / & / & / & / & / & / \\
\hline$\Delta \mathrm{H}_{\mathrm{m}}(\mathrm{J} / \mathrm{g})$ & 72 & 72 & / & / & 111 & 108 & / & / & / & / & / & / \\
\hline$\Delta \mathrm{H}_{\mathrm{m} 100 \%}(\mathrm{~J} / \mathrm{g})$ & $135^{d}$ & $135^{\mathrm{d}}$ & / & / & $151^{\mathrm{e}}$ & $151^{\mathrm{e}}$ & / & / & / & / & / & / \\
\hline$\chi_{c}(\%)$ & 53.3 & 53.3 & / & l & 73.5 & 71.5 & / & l & / & / & / & l \\
\hline $\mathrm{T}_{\mathrm{m} 2}{ }^{\mathrm{f}}\left({ }^{\circ} \mathrm{C}\right)$ & $41 / 45 / 47$ & $50 / 55$ & / & / & $9 / 25 / 47$ & $30 / 53$ & / & l & / & / & / & I \\
\hline $\mathrm{T}_{\mathrm{c}}\left({ }^{\circ} \mathrm{C}\right)^{\mathrm{g}}$ & 24 & 29 & I & I & 33 & 38 & I & I & I & I & I & I \\
\hline
\end{tabular}
a) Taken at the midpoint
b) Hardly detectable
c) Melting temperature during the first heating scan
d) From reference [44]
e) From reference [45]
f) Melting temperatures during the second heating scan
g) Crystallization temperature during the intermediate cooling stage 
Table 3. Absolute molar masses of the TPUs determined from SEC/triple detection

\begin{tabular}{|c|c|c|c|c|c|}
\hline polyester starting diol & polyester polyol & $\begin{array}{c}\mathrm{M}_{\mathrm{n}} \text { polyol } \\
\text { (titration, g.mol }{ }^{-1} \text { ) }\end{array}$ & HS \% & $\mathrm{M}_{\mathrm{n}}\left(\mathrm{kg} \cdot \mathrm{mol}^{-1}\right)$ & $\mathrm{M}_{\mathrm{w}}\left(\mathrm{kg} \cdot \mathrm{mol}^{-1}\right)$ \\
\hline \multirow{4}{*}{ BDO } & AA-BDO-1 & 1250 & $\begin{array}{l}30 \\
40 \\
50\end{array}$ & $\begin{array}{l}50.0 \\
45.5 \\
45.4\end{array}$ & $\begin{array}{l}118.0 \\
101.5 \\
116.0\end{array}$ \\
\hline & AA-BDO-3 & 3550 & $\begin{array}{l}30 \\
40 \\
50\end{array}$ & $\begin{array}{l}36.2 \\
31.1 \\
45.7\end{array}$ & $\begin{array}{c}101.0 \\
84.0 \\
114.5\end{array}$ \\
\hline & MGA-BDO-1 & 1400 & $\begin{array}{l}30 \\
40 \\
50\end{array}$ & $\begin{array}{l}33.5 \\
37.7 \\
45.8\end{array}$ & $\begin{array}{c}71.0 \\
88.5 \\
122.0\end{array}$ \\
\hline & MGA-BDO-3 & 2640 & $\begin{array}{l}30 \\
40 \\
50\end{array}$ & $\begin{array}{l}21.1 \\
28.4 \\
36.2\end{array}$ & $\begin{array}{l}47.2 \\
58.8 \\
68.3\end{array}$ \\
\hline \multirow{2}{*}{ HDO } & AA-HDO-1 & 1160 & $\begin{array}{l}30 \\
40 \\
50\end{array}$ & $\begin{array}{l}58.3 \\
43.5 \\
66.5\end{array}$ & $\begin{array}{c}114.3 \\
80.9 \\
123.0\end{array}$ \\
\hline & MGA-HDO-1 & 1140 & $\begin{array}{l}30 \\
40 \\
50\end{array}$ & $\begin{array}{l}47.4 \\
43.0 \\
61.4\end{array}$ & $\begin{array}{c}90.0 \\
87.2 \\
173.5\end{array}$ \\
\hline \multirow{2}{*}{ MPDO } & AA-MPDO-1 & 1750 & $\begin{array}{l}30 \\
40 \\
50\end{array}$ & $\begin{array}{l}50.0 \\
40.6 \\
40.8\end{array}$ & $\begin{array}{c}181 \\
130.6 \\
121.1\end{array}$ \\
\hline & MGA-MPDO-1 & 1690 & $\begin{array}{l}30 \\
40 \\
50\end{array}$ & $\begin{array}{l}54.0 \\
36.1 \\
43.6\end{array}$ & $\begin{array}{c}155.0 \\
84.3 \\
118.0\end{array}$ \\
\hline
\end{tabular}


Table 4. Thermal transitions and degradation temperatures of the segmented polyurethanes

\begin{tabular}{|c|c|c|c|c|c|c|c|c|}
\hline TPU & $\begin{array}{l}\text { Hardness } \\
\text { (Shore A) }\end{array}$ & $\mathrm{T}_{\mathrm{g}} 1^{\text {st }} \operatorname{scan}\left({ }^{\circ} \mathrm{C}\right)^{\mathrm{a})}$ & $\mathrm{T}_{\mathrm{g}} 2^{\text {nd }} \operatorname{scan}\left({ }^{\circ} \mathrm{C}\right)^{\mathrm{a})}$ & $\mathrm{T}_{\mathrm{m}} 1^{\text {st }} \operatorname{scan}\left({ }^{\circ} \mathrm{C}\right)^{\mathrm{a})}$ & $\mathrm{T}_{\mathrm{m}} 2^{\text {nd }} \operatorname{scan}\left({ }^{\circ} \mathrm{C}\right)^{\mathrm{a})}$ & $T \alpha\left({ }^{\circ} \mathrm{C}\right)^{b}$ & $\mathrm{~T}_{\mathrm{d} 5 \%} \mathrm{~N}_{2}\left({ }^{\circ} \mathrm{C}\right)^{\mathrm{c})}$ & $\mathrm{T}_{\mathrm{d} 5 \%} \operatorname{air}\left({ }^{\circ} \mathrm{C}\right)^{\mathrm{C})}$ \\
\hline AA-BDO-1-30\% & $64 \pm 1$ & -38 & -22 & 161 & 134 & -30 & 325 & 325 \\
\hline AA-BDO-1-40\% & $82 \pm 1$ & -39 & -26 & $153 / 174$ & 163 & -26 & 324 & 325 \\
\hline AA-BDO-1-50\% & $94 \pm 1$ & -32 & -14 & $139 / 216$ & 175 & -11 & 320 & 319 \\
\hline MGA-BDO-1-30\% & $62 \pm 2$ & -38 & -24 & 156 & 143 & -25 & 312 & 324 \\
\hline MGA-BDO-1-40\% & $80 \pm 2$ & -33 & -25 & $156 / 203$ & 169 & -22 & 314 & 322 \\
\hline MGA-BDO-1-50\% & $94 \pm 1$ & -30 & -21 & $156 / 190 / 221$ & 180 & -14 & 313 & 319 \\
\hline AA-BDO-3-30\% & $94 \pm 1$ & -50 & -45 & $38 / 177$ & $40 / 174$ & & 327 & 327 \\
\hline AA-BDO-3-40\% & $96 \pm 1$ & -45 & -40 & $43 / 205$ & 179 & $N D^{d)}$ & 322 & 323 \\
\hline AA-BDO-3-50\% & $96 \pm 1$ & -47 & -32 & $36 / 190 / 224$ & $184 / 210$ & & 320 & 322 \\
\hline MGA-BDO-3-30\% & $66 \pm 1$ & -43 & -38 & 167 & 169 & & 318 & 325 \\
\hline MGA-BDO-3-40\% & $86 \pm 2$ & -46 & -40 & 215 & $189 / 205$ & $N D^{d)}$ & 311 & 322 \\
\hline MGA-BDO-3-50\% & $95 \pm 1$ & -44 & -38 & $216 / 220$ & $185 / 207 / 220$ & & 312 & 318 \\
\hline AA-HDO-1-30\% & $59 \pm 2$ & -33 & -19 & - & 114 (?) & -21 & 318 & 330 \\
\hline AA-HDO-1-40\% & $79 \pm 1$ & -28 & -8 & $164 / 183$ & 145 & -16 & 319 & 321 \\
\hline AA-HDO-1-50\% & $93 \pm 1$ & -24 & -6 & $158 / 200 / 207$ & 171 & -7 & 314 & 321 \\
\hline MGA-HDO-1-30\% & $59 \pm 2$ & -30 & -17 & - & - & -19 & 313 & 328 \\
\hline MGA-HDO-1-40\% & $79 \pm 1$ & -28 & -14 & $162 / 185$ & 151 & -17 & 313 & 320 \\
\hline MGA-HDO-1-50\% & $91 \pm 1$ & -24 & -7 & $158 / 207$ & 171 & -8 & 304 & 321 \\
\hline AA-MPDO-1-30\% & $57 \pm 2$ & -39 & -24 & $173(?)$ & 151 & -30 & 319 & 329 \\
\hline AA-MPDO-1-40\% & $79 \pm 2$ & -38 & -29 & $165 / 206$ & 172 & -29 & 315 & 322 \\
\hline AA-MPDO-1-50\% & $92 \pm 1$ & -36 & -18 & 170/203/212 & 182 & -23 & 317 & 323 \\
\hline MGA-MPDO-1-30\% & $58 \pm 2$ & -33 & -20 & - & - & -23 & 312 & 327 \\
\hline MGA-MPDO-1-40\% & $79 \pm 2$ & -30 & -20 & $160 / 180 / 200$ & 169 & -18 & 310 & 322 \\
\hline MGA-MPDO-1-50\% & $92 \pm 1$ & -27 & -12 & $208 / 215$ & 183 & -19 & 312 & 319 \\
\hline
\end{tabular}

a) From DSC measurements ( $1^{\text {st }}$ and $2^{\text {nd }}$ heating scans at $20^{\circ} \mathrm{C} / \mathrm{min}$ )

b) From dynamic mechanical analysis (heating scan at $3^{\circ} \mathrm{C} / \mathrm{min}$ )

c) From thermogravimetric analysis $\left(10^{\circ} \mathrm{C} / \mathrm{min}\right) ; T_{d 5 \%}$ corresponds to a $5 \%$ weight loss

d) Not determined 
Table 5 : Hysteresis during tensile testing for the first, second and tenth loading/unloading cycles to nominal strains 100,400 or $800 \%$.

\begin{tabular}{|c|c|c|c|c|}
\hline Material & Max. nominal strain \% & $\begin{array}{c}1^{\text {st }} \text { cycle hysteresis } \\
\Delta \mathrm{W}^{\mathrm{a})}\left(\mathrm{MJ} . \mathrm{m}^{-3}\right)\end{array}$ & $\begin{array}{c}2^{\text {nd }} \text { cycle hysteresis } \\
\Delta \mathrm{W}^{\text {a) }}\left(\mathrm{MJ}^{-3} \mathrm{~m}^{-3}\right)\end{array}$ & $\begin{array}{c}10^{\text {th }} \text { cycle hysteresis } \\
\Delta \mathrm{W}^{\text {a) }}\left(\mathrm{MJ}^{-\mathrm{m}^{-3}}\right)\end{array}$ \\
\hline \multirow{2}{*}{ AA-BDO-1 30\% } & 100 & 0.47 & 0.19 & 0.134 \\
\hline & 400 & 8.24 & 3.12 & 1.96 \\
\hline \multirow{2}{*}{ MGA-BDO-1 30\% } & 100 & 0.61 & 0.25 & 0.17 \\
\hline & 400 & 8.17 & 2.06 & 1.30 \\
\hline \multirow{3}{*}{ AA-BDO-1 40\% } & 100 & 1.69 & 0.69 & 0.52 \\
\hline & 400 & 19.67 & 6.82 & 4.17 \\
\hline & 800 & 60.79 & 19.60 & 11.72 \\
\hline \multirow{3}{*}{ MGA-BDO-1 40\% } & 100 & 2.35 & 0.78 & 0.55 \\
\hline & 400 & 23.55 & 6.03 & 3.40 \\
\hline & 800 & 64.54 & 14.08 & 7.68 \\
\hline \multirow{2}{*}{ AA-BDO-1 50\% } & 100 & 4.64 & 1.80 & 1.27 \\
\hline & 400 & 42.06 & 12.40 & 7.74 \\
\hline \multirow{3}{*}{ MGA-BDO-1 50\% } & 100 & 5.25 & 1.95 & 1.36 \\
\hline & 400 & 45.17 & 10.83 & 6.46 \\
\hline & 800 & 124.22 & 27.15 & 15.78 \\
\hline \multirow{3}{*}{ AA-HDO-1 40\% } & 100 & 1.11 & 0.46 & 0.34 \\
\hline & 400 & 14.59 & 5.05 & 3.35 \\
\hline & 800 & 48.44 & 16.34 & 10.65 \\
\hline \multirow{3}{*}{ MGA-HDO-1 40\% } & 100 & 1.34 & 0.57 & 0.41 \\
\hline & 400 & 16.25 & 5.20 & 3.25 \\
\hline & 800 & 46.67 & 14.61 & 8.52 \\
\hline
\end{tabular}

a) Integration of the whole load-unload sequence 
